This item was submitted to Loughborough's Research Repository by the author.

Items in Figshare are protected by copyright, with all rights reserved, unless otherwise indicated.

\title{
Low flow response surfaces for drought decision support: A case study from the UK
}

PLEASE CITE THE PUBLISHED VERSION

http://dx.doi.org/10.1142/S2345737615500050

\section{PUBLISHER}

(C) World Scientific Publishing

\section{VERSION}

AM (Accepted Manuscript)

\section{PUBLISHER STATEMENT}

This work is made available according to the conditions of the Creative Commons Attribution-NonCommercialNoDerivatives 4.0 International (CC BY-NC-ND 4.0) licence. Full details of this licence are available at: https://creativecommons.org/licenses/by-nc-nd/4.0/

\section{LICENCE}

CC BY-NC-ND 4.0

\section{REPOSITORY RECORD}

Prudhomme, Christel, Eric Sauquet, and Glen Watts. 2019. "Low Flow Response Surfaces for Drought Decision Support: A Case Study from the UK". figshare. https://hdl.handle.net/2134/20916. 


\section{Journal of Extreme Events \\ Low flow response surfaces for drought decision support: a case study from the UK --Manuscript Draft--}

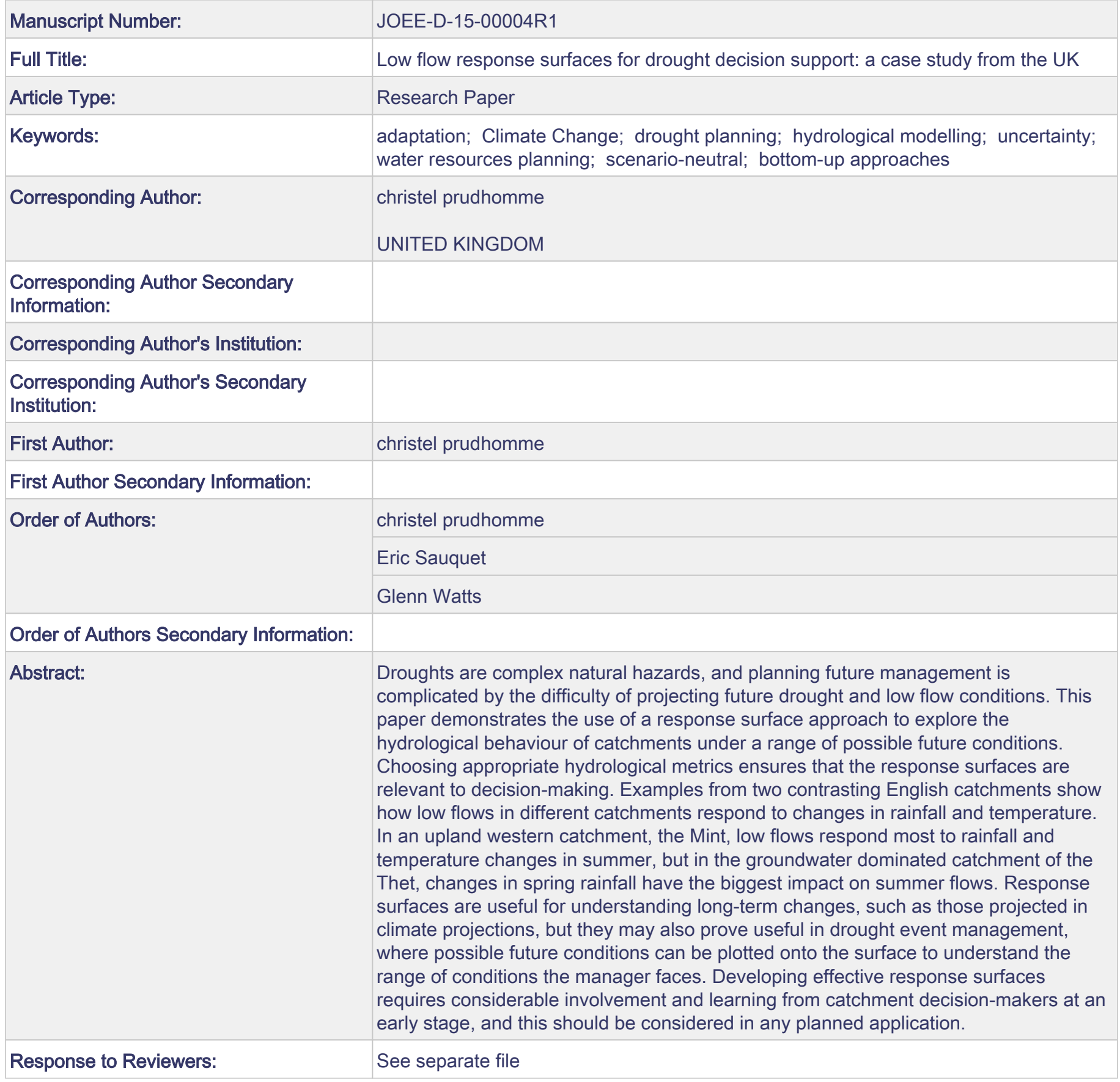




\title{
JOEE-D-15-00004 - 'Low flow response surfaces for drought decision support: a case study from the UK' by Prudhomme, Sauquet and Watts
}

\author{
Response to reviewers
}

Dear Dr. Murphy

We would like to thank you and the three anonymous reviewers for the positive feedback on our paper and the advice of minor revision to our manuscript. As suggested, see below the detailed response to the comments sent by each reviewer. We hope you will find our revised manuscript suitable for publication in JOEE

\section{Yours sincerely}

Christel Prudhomme on behalf of the authors

\section{\#\#\#\#\#\#\#\#\#\#\#\#\#\#\#\#\#\#\#\#\#\#\#\#\#\#\#\#\#}

Reviewers' comments:

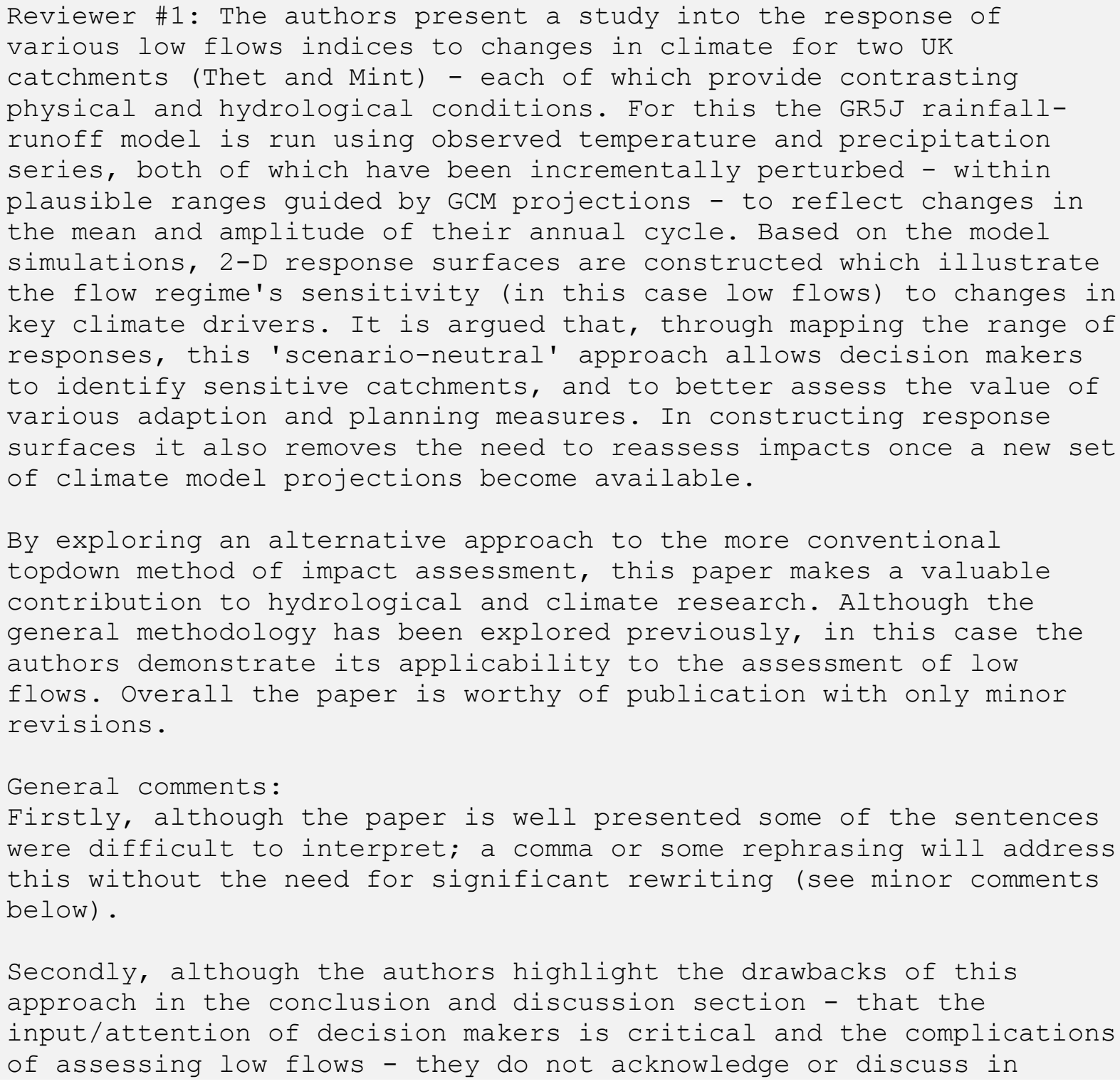


detail any further assumptions/limitations of the approach (e.g. phase does not change and peaks in January; the significance to the flow regime of changes in higher statistical moments). This would add to the paper and aid in the interpretation of the response surfaces.

Thirdly, the authors should consider including in the results section a short analysis of the climate elasticity of the catchments. This constitutes an interesting step in the process of refining the indicators and estimating the catchment response to altered climate forcing; however this is at the discretion of the authors.

Thank you for your positive feedback and your constructive suggestions. We have tried as much as possible to simplify the text throughout the manuscript to help with the clarity. As suggested we also have added some text about the limitation of the method, in particular the influence of the climate scenarios explored. We have also added some results from the national elasticity analysis in the manuscript.

Comments about rewording and text editing have been addressed as much as possible. The rest of the comments are discussed in detail below.

Equation 4: it is a little confusing that $t$ is identified as the index for both the monthly and daily values.

In all equations $t$ has been replaced by $d$ for daily values.

Page 9: The authors should provide a more comprehensive starting paragraph in the results section. Here a synopsis of the study should be given; additionally the aims/results should be stated.

Following reviewer 3 comments, we have restructured the manuscript. We believe this now provides a much better flow to the work and appropriate description to the aims and results.

Reviewer \#2:

General comments:

This manuscript deals with the applicability of the bottomup/response surface approach in the context of climate impact on droughts and water management. Based upon a case study of two catchments that represent two different low flow generation processes, the added value of responses surfaces but also the challenges in their usage is demonstrated.

The manuscript is of great relevance not only for researchers but also for practitioners and other stakeholders, and hence fits perfectly into the audience of JoEE. Especially, it is of importance for estimating the vulnerability of the system towards hydrological droughts and risk assessment - not only towards climate change related impacts but also to climate impacts on much smaller temporal scale (seasonal forecasts).

It was a pleasure to read the manuscript; it is comprehensive, concise, and still easy to read. I have only same minor issues that should be fixed before publication, but most of them are really minor.

Hence, I recommend minor revisions. 
We would like to thank the reviewer for their positive feedback about our paper. We have addressed as much as possible all comments about text editing and re-wording. We have also redone most of the figures and simplified the figure captions. The rest of the comments have been addressed as follow:

Page 4, last paragraph:

"the day corresponding to the maximum of the mean daily flow" - by "mean daily flow" you mean the maximum of the mean annual hydrograph? Please, clarify meaning.

We have not edited the text for clarity.

Page 5, first paragraph:

"slightly longer Q90_dur_5yr (Figure 2)" - I can't find it in Figure 2 .

This is correct it should have been Table 2 . The text has been corrected.

Page 5, second last paragraph: Please add the temporal resolution (daily) and the used meteorological stations and meteorological parameters

Done.

Page 5, last paragraph and Figure 4, also Figure captions Figure 4 on page 6:

I think indication for panels Mint and Thet have been interchanged. In the text you state "Note the better fit for the Mint", and in Figure 4 the better fit is for river Thet.

We are sorry for the confusion; figure $2 \mathrm{a}$ and $2 \mathrm{~b}$ were reversed. This has now been corrected.

In general: Please unify the indications in the Figure (sometime "left and "right", sometimes "a and b") throughout the entire manuscript. In addition, I would prefer to have also the names of the two catchments in the figure itself to improve readability.

We have now added figure titles and legend panel in most graphs to improve readability and simplified the figure captions throughout.

Page 6, third paragraph: "and were applied here to the full observational record." - Please add time period. (1961-2011)?

Done.

Page 6, fourth paragraph: "rainfall and precipitation" - I guess you meant "temperature".

Correct. This has now been rectified.

Page 7, first paragraph: please add a definition on "seasonal" and how you used it like in "seasonal semi-amplitudes"

'Seasonal' was only used to refer to the annual phase, hence trough and peak of the function vary seasonal. We agree this was confusing and have removed reference to seasonal.

(*) Page 8, first paragraph: How are the different monthly scenarios combined in the response surface. Figure 5 suggest that there are different annual "pathways" - some with nearly evenly changes over 
the year, some with huge differences. I assume that different monthly treatments can lead to the same indicator value. How are these values combined?

The reviewer is right to highlight this point, which we have now clarified in the manuscript by adding the following text. 'The response surfaces are constructed by plotting the hydrological indicator derived from a given climate scenario, the $(x, y)$ coordinates given by the scenarios' climate indicators. Some climate indicators however can have the same value while resulting from different scenarios and annual pathways (e.g. precipitation mean annual change). This means that a same point on the response surface can be associated with different hydrological indicator values. In this case, response surfaces are interpolated based on the minimum, mean and maximum response to capture the range and associated uncertainty in the climate-to-low-flow response. For clarity only the response surfaces based on the mean of all responses are shown in the paper.'

Page 8, Equation 6 description: please explain $x(t)$, and $y(t)$

This has now been clarified

Page 9, first paragraph, last sentence: Ok, but wouldn't the increased $\mathrm{P}$ enhance PET as more water is available?

This is correct: $\mathrm{P}$ and PET would increase at the same rate until PET is completely satisfied, and then increase in $\mathrm{P}$ would lead to increase in flow. However increase in T would not necessarily change PET already limited. We have revised the text to clarify.

Page 9, second paragraph: I would recommend to refuse a comparison between response surfaces as the scales are not comparable. E.g., I cannot see a "clearer relationship" as the scale between Thet and Mint are different; the Mint RS covers a much wider range. Maybe you can normalize the low flow indicators, but this would impede the interpretation of the values.

We understand the point of the reviewer (albeit in this paragraph the comparison was that of two indicators for the same catchment), and have revised the text. We also agree than normalisation of the low flow indicator would not be particularly useful and have not changed this. We hope the text is now more appropriate.

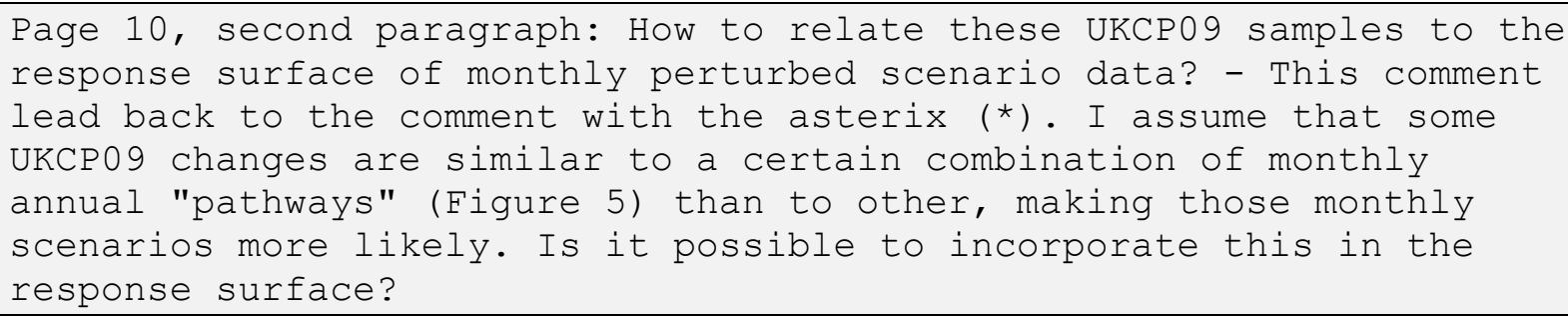

Again this is a good point and we have clarified the text. The UKCP09 scenarios are provided as monthly and seasonal factors. For the paper we have selected the seasonal factor or calculated the 6-month factor from the sample, and have ignored the rest of the annual pathway, as our graphic was intended to illustrate the method. We have added the follow text highlighting this uncertainty as suggested by the reviewer 'Here only the value of climate change factors for the season represented in the response surface was considered and the within-year variability of each UKCPO9 scenarios was ignored. This means that the whole annual pathway of some UKCPO9 scenarios might be very different from that of the scenarios explored in the sensitivity framework. A more sophisticated method could be used where a sine curve would be fitted to each UKCPO9 monthly scenarios and higher likelihood weights given to scenarios closest to those used in the sensitivity framework.' 
Page 15, 7.1.: "The 10th percentile daily flow" - please add: based upon the entire observational data set (19xx- XXXX)

We have now edited the text and added 'calculated over the relevant period'.

Figure caption figure 2:

-"period of available observations" add years (XXXX-XXXX)

- "Water years are ranked according" to

- "and grey circle show" -> and grey circle accumulatively shows

- "incomplete water years" -> 20\% of incomplete data. That is

surpringly huge.

We have re-done figure 2 , have made more explicit the meaning of the different symbols within the figure and simplified the figure caption. Note that the $20 \%$ does not refers to the total number of missing values but to the number of years with at least 1 day missing.

Figure 3: legend missing. Meaning of the different line types

We have now added a legend within the figure.

Reviewer 3

This study demonstrates a practical implication of the scenarioneutral framework in climate impact assessments, to overcome the uncertainty problems associated with the traditional scenario-led approach. The plausible ranges of future changes in temperature (and thus $\mathrm{PET}$ ) and precipitation are determined, within which response surfaces of four low-flow indices are constructed. The study show contrasting results for two catchments, from which the catchment with lower storage capacity (i.e. Mint) show less delay climate-toflow effects, and less response to temperature changes due to low AET comparing to PET. The response surfaces are then overlaid with the UKCPO9 probabilistic sample climate change factors, which implies that the low-flow at Mint can be more vulnerable to potential climate change but with higher uncertainties. However, the scenario-neutral framework provides great flexibility and convenience for decision makers to visualize the bigger picture of climate impact, and update new climate projections and assess the associated climate impact. Scenario-neutral framework has great potential for many practical applications in climate impact assessment but it is a relatively new area with low number of application-type studies, therefore, this study can be a valuable addition to the existing literature in climate impact assessment, which is highly relevant to this Journal.

My general suggestions are as below, and please also refer to the attachments for specific comments.

1. The current manuscript has some crossover among the Methodology, Results and Discussion sections. It is thus suggested that the structure of these sections is revised to address the following:

1) Distinguish the contents in these sections better;

2) Sub-divide sections if necessary and organize them in suitable orders to improve the flow.

In these ways the clarity of the entire paper can be greatly improved. 
2. Following Comment \#1, the current manuscript seems a bit

disconnected where the analyses with UKCPO9 samples are presented in the Discussion where nearly one entire paragraph has been used for introducing the relevant methodology. In my opinion this analysis really is a highlight of this study, so it may better suit into the main results rather than discussion - the author may consider extending the boundaries of the plausible ranges of the climate drivers to include the UKCP09 samples discussed in Section 4. I understand that there can be substantial work involved, but the in this way the overall flow and the relevance of this study to practical drought management could be greatly improved. If this is agreed by the authors these analyses can be included in additional sub-section in the Results.

3. The methodology should be better explained to ensure that details such as use of models, equations and data are explained and justified.

4. The figures can be greatly improved with the use of associated legends.

We would like to thank the reviewer for their positive comments and constructive suggestions to improve the manuscript. As suggested we have changed the structure of the manuscript to improve the flow of the paper. We have detailed below how we have addressed other comments in details, except typos, missing reference, legend improvement and comments already addressed in the responses to previous reviewers.

Comment 3 page 5: 'Could you provide more explanation? The length of the dashed brown arrows has not been explained before so it is a bit confusing here.'

Comments 1 to 3, figure 2: 'Is there a better term than occurrence' [...] 'And are they f6rthe dashed b34e c5rc3e, shaded grey circle, or both'

We agree explanation of the figure should have been given in the main body of text. This has now been added. We have also revised the figure captions for clarity (comments Figure 2).

Comment 2 page 6: 'If this is only for precipitation it should be clearer to use $P$ instead of $X$ - just as how you use $T$ in eqn $2^{\prime}$

We have now modified Equation 1.

Comment 1 page 7: ' 'mean annual change' - this is the same as $\mathrm{X} 0$ in the following sentence - seems like you are referring to the individual 'monthly changes' from Figure 5'

A slight complication is introduced for temperature scenarios which follow a modified cosine function where the mean annual change is also dependant on the semi-amplitude. We have introduced a new notation in the equations to distinguish between the semi-amplitudes applied to precipitation and temperature scenarios for clarity. 
Comments page 5 on NSE error measures

We have now added the equations associated with $\mathrm{NSE}_{\text {SQRT }}$ and $\mathrm{NSE}_{\text {Inv }}$ and added some text about their particular use and difference.

Comment on Figure 8

The text describing the Q90 response surfaces of the Mint in relationship UKCP09 scenario is correct, but to save space the figure was not included within the manuscript. The description of the response surfaces for the Mint and its association with UKCO9 scenarios is described later on in the paragraph. 
Low flow response surfaces for drought decision support: a case study from the UK

2

3 Christel Prudhomme*1,2, Eric Sauquet ${ }^{3,1}$, Glenn Watts ${ }^{4,5}$

4 1. Centre for Ecology and Hydrology, Wallingford, OX10 8BB, UK

5 2. Department of Geography, Loughborough University, LE11 3TU, UK

6

7

Main body work count: 8829

Prepared for Journal of Extreme Events (Special Issue)

\section{Abstract} considered in any planned application.

Keywords planning; scenario-neutral; bottom-up approaches

Droughts are complex natural hazards, and planning future management is complicated by the difficulty of projecting future drought and low flow conditions. This paper demonstrates the use of a response surface approach to explore the hydrological behaviour of catchments under a range of possible future conditions. Choosing appropriate hydrological metrics ensures that the response surfaces are relevant to decision-making. Examples from two contrasting English catchments show how low flows in different catchments respond to changes in rainfall and temperature. In an upland western catchment, the Mint, low flows respond most to rainfall and temperature changes in summer, but in the groundwater dominated catchment of the Thet, changes in spring rainfall have the biggest impact on summer flows. Response surfaces are useful for understanding long-term changes, such as those projected in climate projections, but they may also prove useful in drought event management, where possible future conditions can be plotted onto the surface to understand the range of conditions the manager faces. Developing effective response surfaces requires considerable involvement and learning from catchment decision-makers at an early stage, and this should be

adaptation; climate change; drought planning; hydrological modelling; uncertainty; water resources 


\section{Introduction and background}

35

Droughts are complex natural hazards, with the threat they pose reflecting not only atmospheric, hydrological and biogeophysical processes (Touma et al. 2015) but also the way that people interact with and manage water (Sofoulis 2005, Watts et al. 2012, Lloyd-Hughes 2014)). While droughts are a problem for most of the world (Kallis 2008), universal definitions are probably impossible (LloydHughes 2014), though in broad terms all droughts are caused by a deviation below long-term average rainfall (Tallaksen and Van Lanen 2004). In temperate climates such as northern Europe, this complexity means that historical major droughts show different spatial and temporal footprints (Parry et al. 2012), partly because every drought develops differently. For example, in the English lowlands, no single large scale atmospheric driver can explain the occurrence of multi-annual droughts (Folland et al. 2014).

With poor predictability of drought initiation and termination (Weisheimer and Palmer 2014), water managers must plan for a range of different possible droughts, usually relying on past experience and historical records to provide the context for their plans. However, even this presents problems. There are relatively few droughts in the instrumental historical record, and there is no reason to expect that droughts of recent decades present a full picture of possible droughts under the current climate. For example, in the UK, twentieth century droughts typically lasted no longer than two years, but in the nineteenth century several droughts were of much greater duration (Jones et al. 2006, Marsh et al. 2007). As a result, water supply planning tends to take a precautionary approach, with long-term plans based on hydrological variability supplemented by drought plans that can cope with a wide range of possible conditions (Spraggs et al. 2015, Watts et al. 2012, Wilhite et al. 2007).

As the climate changes in response to anthropogenic emissions of greenhouse gases, drought frequencies and characteristics are also expected to change globally (Prudhomme et al. 2014) and in Europe (e.g Vidal et al. 2012, Prudhomme et al. 2012). However, the regional picture is much less clear, partly because of Global Climate Model (GCM) uncertainties (Stocker et al. 2013) and also because of the difficulty of downscaling GCM results to a scale relevant to drought management decisions (Ekström et al. 2015). This makes the conventional 'top down' climate change impact study particularly problematical for drought management: new hydrological projections for a given region may be markedly different from previous results, necessitating a new impact study and possibly requiring a new drought plan. Such difficulties have led some authors to question the utility of climate change impact studies for developing robust adaptation plans; instead they advocate 'bottom up' approaches (Wilby and Dessai 2010).

Concerns over the value of impact studies have led to the development of the scenario-neutral approach. In this, changes in a policy-relevant indicator are calculated for a range of plausible climatic changes, with the results shown as response surfaces (Prudhomme et al. 2010). Understanding the response to a range of possible changes has several benefits. As new climate projections become available, these can be mapped onto the response surface, hence avoiding the need for new impact studies every time climate models change. Perhaps more importantly, the shape of the response surface helps the decision-maker understand the changes to which the system is most sensitive, encouraging management responses that are robust to a range of feasible changes. In some respects the scenario-neutral approach is similar to Robust Decision Making (RDM, Lempert et al. 2006) and Decision Scaling (Brown et al. 2012) but does not try to model the impact of strategies or decisions. 
Instead the scenario-neutral approach illustrates the response of the system indicator to change, leaving decisions firmly situated with the decision-maker. This may be desirable for some decisionmakers, who may prefer this clear separation of science and policy (Gluckman 2014). Scenario-neutral approaches have been used successfully in a number of water management questions, including seasonal river flows in large rivers in Europe (Weiß 2011), lake water levels in Sweden (Wetterhall et al. 2011) and the USA (Brown et al. 2011), changes in flood peaks in the UK (Prudhomme et al. 2013), and changes in urban water supply robustness in the USA (Whateley et al. 2014).

This paper demonstrates the utility of the scenario-neutral approach in planning future drought management by considering low flow response surfaces for two contrasting English catchments from northwest and eastern England. The approach consists first of identifying appropriate indicators that are relevant to drought management, next using hydrological modelling to develop response surfaces for these indicators, and then interpreting these indicators to illuminate the challenges that catchment managers face. The paper finishes with a discussion of the benefits and difficulties of using the scenario-neutral approach in this way.

\section{Data and methods}

\subsection{Case study}

The analysis was conducted on two contrasting English catchments: the Mint at Mint Bridge in Cumbria, north west England (National River Flow Archive NRFA number 73011) and the Thet at Bridgham in Norfolk, in eastern England (NRFA number 33044) (Table 1 and Figure 1).

The Mint is a small upland catchment of just under $70 \mathrm{~km}^{2}$, with annual average rainfall of more than $1500 \mathrm{~mm}$ but only around $400 \mathrm{~mm}$ of evaporation, resulting in an average annual runoff of nearly $1200 \mathrm{~mm}$. The catchment is largely impermeable and fast-responding. This catchment is used here to be representative of typical upland catchments in Wales and western and northern England. In such catchments, water supply is usually provided by reservoirs formed by building an impounding dam across a valley, capturing all of the upstream flow. In the UK, such reservoirs typically fill every winter but are susceptible to intense spring and summer droughts, with the lowest levels reached in autumn. There are several problems in managing such supply systems. Droughts can develop very quickly during a single year, but as a series of consecutive dry months is very unusual it would not be prudent to take drought measures after one or two dry months. However, as a severe drought develops there are often very few options to enhance supplies.

In contrast, the Thet is typical of a lowland catchment with limited rainfall (just over $600 \mathrm{~mm}$ ) but a similar level of potential evapotranspiration, which means that the average annual runoff is only around $140 \mathrm{~mm}$ in this $280 \mathrm{~km}^{2}$ catchment. The mixture of permeable chalk overlain by clay means that the catchment responds relatively quickly to heavy rainfall events, but also has a relatively high baseflow flow index (BFI, Gustard et al. 1992) of 0.74 showing a groundwater-dominated regime. Located in an agricultural region with high irrigation needs, the Thet is typical of a catchment requiring careful water management planning partly because of conflicting water needs. Public water supply systems in such catchments typically combine groundwater abstraction with pumped storage reservoirs, and are generally resilient to single year droughts but are stretched by longer droughts, particularly when there are consecutive dry winters with limited groundwater recharge. At the same 
time, agricultural abstraction can be limited towards the end of a single dry summer. Under climate change, warmer temperature are expected to drive higher water needs by crops but this may not be compensated by changes in rainfall patterns: for example, in the latest UK projections, rainfall is projected to increase during winters but not in summer (Murphy et al. 2009).

Average catchment daily time series were extracted from $1 \mathrm{~km}^{2}$ resolution Gridded Estimates of Areal Rainfall GEAR data set (Keller et al. 2015, Tanguy et al. 2014) for precipitation and the $5 \mathrm{~km}$ Met Office UKCP09 data set (Perry et al. 2009) for temperature. Average catchment monthly potential evapotranspiration PET was extracted from the Met Office Rainfall and Evaporation Calculation System MORECS (Thompson et al. 1982) and uniformly converted to daily PET. Daily discharge data and catchment information was available from the National River Flow Archive.

Table 1. Main characteristics of the two basins. Statistics are computed on records available within the period 01/01/1961 to 31/12/2011 (1: from http://www.ceh.ac.uk/data/nrfa/index.html)

Figure 1. Location of case study catchments: A: Mint at Mint Bridge; B: Thet at Bridgham. Grey shading shows the main aquifers.

\subsection{Hydrological regime and associated indices}

The first stage in the response surface approach is to identify decision-relevant indices that can be characterised using appropriate hydrological models. The success of the approach depends on finding indices that are both useful for decisions and sensitive to changes in climate. For this case study, four hydrological indices were selected for their relevance for water management and their complementarity in describing the different components of low flow regime:

1. daily flow exceeded $90 \%$ of the time on average (Q90);

2. mean daily flow between April and September (QAS);

3. annual maximum duration with flow continuously below Q90 with a 5 year return period (Q90_dur_5yr); and

4. date when flow first falls below Q90 (Q90_day_1).

Details of the calculation are given in the appendices. Q90 and QAS characterise water resource available during the drier spring and summer months. Q90_dur_5yr characterises the duration of severe low flow events. Q90_day_1 is an indicator of seasonality. Table 2 (next section) gives values of each hydrological index for the two case study catchments. QAS and Q90 are expressed in $\mathrm{mm}$ to allow comparison with climate forcing.

Figure 2 shows, for both catchments, the recorded low flow periods within each water year, defined as flow below Q90, in a circular diagram. The water year has also been calculated for each catchment, and its start is displayed as a black dot. In England, the conventional definition of the water year begins on 1 October. Here we calculate a dynamic low flow water year centred on the low flow period. The start of the water year is defined as the average day associated with the annual maximum mean daily flow, and is computed for each catchment. This approach allows analysis of the way catchment hydrological response changes with climate change. In the Mint, low flow periods start in early June and end in late August while they are delayed by around 1 month in the Thet (starting in early July and ending in late September). The Mint is also associated with large variability of flow, with only $10 \%$ of years without periods under Q90, against nearly $30 \%$ in the Thet (dashed inner circle). This is likely to be due to low storage capacity to sustain flows during period of no rain in the Mint. As a result, the 
water year also starts later in the Mint than in the Thet, as high flow from the recharge season continue into winter (late January and early January, respectively). The baseflow regime also influences when low flow occurs in the year, with more episodes of continuous low flow (length of orange lines in Figure 2) and slightly longer Q90_dur_5yr (Table 2) found in the Thet than in the Mint. In contrast, the flashier regime of the Mint results in a larger variability in the start of the low period periods compared with that in the Thet.

Figure 2. Circular diagram of the periods of flow below Q90 recorded during each water year with available observations for the Mint at Mint Bridge and the Thet at Bridgham, ranked by increasing duration of low flow period. The radius of the dashed blue inner circle gives the proportion of water years without any recorded flow below Q90. The thickness of the grey ring gives the proportion of incomplete years with flow below Q90.

\subsection{Sensitivity framework}

The next stage in developing a sensitivity framework is to identify the climatic parameters for the response surface. Following Prudhomme et al. (2010), the sensitivity of the catchments' low flow regime to climatic changes was quantified from changes in precipitation and temperature. The range and seasonality of changes tested were chosen to encompass the range of climate changes in Western Europe from CMIP5 projections including both uncertainty in atmospheric forcing and climate modelling as given by Terray and Boé (2013). The changes represent the absolute deviation from the baseline climatology for both temperature $\left({ }^{\circ} \mathrm{C}\right)$ and precipitation $(\mathrm{mm})$, and were applied here to the full observational climatic record 1961-2011.

As it is not possible to test every possible combination of possible monthly changes in rainfall and temperature, idealised models must be fitted. The effect of seasonality of precipitation change on river flow was accounted for by introducing correction factors $\Delta P$ to the baseline precipitation reference for each month $i, i=1, . ., 12$, through the following cosine function suggested by Prudhomme et al. (2010):

$$
\text { Equation } 1 \quad \Delta P(i)=P_{0}+A_{P} \cdot \cos \left(\left(i-\varphi_{P}\right) \cdot \frac{\pi}{6}\right)
$$

The mean annual change is $P_{0}$ and $A_{P}$ is the semi-amplitude of change (see Wilks 2006 for terminology and equations; semi-amplitude is half the difference between highest and lowest values).

To capture the significant asymmetry of projected ranges of changes in seasonal temperature suggested by Terray and Boé (2013) in Western Europe (minimum in DJF and maximum in JAS), a modified harmonic equation was used to define the factors $\Delta T$ for temperature:

Equation $2 \quad \Delta T(i)=T_{0}+A_{T} \cdot\left[1-\cos \left(\left(i-\varphi_{T}\right) \cdot \frac{\pi}{6}\right)\right]$

The mean annual change associated with Equation 2 is given by $T_{0}+A T$.

Monthly climate change factors were used to perturb the baseline time series to create new input for the hydrological model as follow.

For precipitation, monthly scale factors were applied so that the frequency of dry days is preserved:

$$
P^{*}(d)=P(d) \cdot(\overline{P M}(\operatorname{month}(d))+\Delta P(\operatorname{month}(d)) / \overline{P M}(\operatorname{month}(d))
$$


With $P(d)$ and $P^{*}(d)$ baseline and perturbed precipitation for day $d$ respectively, $\overline{P M}($ month $(d)$ average monthly baseline precipitation for month month $(d)$ and $\Delta P($ month $(d))$ precipitation change factor for month month(d), all in $\mathrm{mm}$.

Perturbed daily temperatures $T^{*}$ for day $d$ (in ${ }^{\circ} \mathrm{C}$ ) were obtained by additive changes:

Equation $4 \quad T^{*}(d)=T(d)+\Delta T(\operatorname{month}(d))$

With $T(d)$ and $T^{*}(d)$ baseline and perturbed daily temperature for day $d$, respectively, and $\Delta T($ month $(d))$ temperature change factor for month month $(d)$, all in ${ }^{\circ} \mathrm{C}$

Changes in potential evapotranspiration PET were calculated (in $\mathrm{mm}$ ) by applying the temperaturebased formula suggested by Oudin et al. (2005) to baseline temperature data. The perturbed PET values are calculated as follows:

Equation $5 \quad P E T^{*}(d)=\max \left(\operatorname{PET}(d)+\frac{R_{a}}{28.5} \frac{(\Delta T(\operatorname{month}(d))+5)}{100} ; 0\right)$

With $\operatorname{PET}(d)$ and $\operatorname{PET}^{*}(d)$ baseline and perturbed potential evapotranspiration for day $d$ in $\mathrm{mm}$, respectively, $R_{a}$ the extra-terrestrial global radiation for the catchment in $\mathrm{MJ} \mathrm{m}^{-2}$ day $^{-1}$, and $\Delta T($ month $(d))$ temperature change factor for month month $(d)$ in ${ }^{\circ} \mathrm{C}$.

\subsection{Rainfall-runoff modelling}

For identifying the catchment responses to climatic changes, a rainfall-runoff model was used so that the hydrological indicators derived from simulations based on the climate scenarios were compared to those derived from simulations based on observed climate. The conceptual lumped rainfall-runoff model GR5J (Le Moine 2008) was used for the hydrological modelling. GR5J is a modified version of GR4J originally developed by Perrin et al. (2003), considered to be well suited to simulating low flow conditions. It was chosen for its ease of calibration and the good performance of the GR4J model across a wide range of riverflow regimes (Zhang et al. 2014, Seiller et al. 2015, Wu et al. 2014, Tian et al. 2013). The GR5J model has five parameters to be fitted (Figure 3): the capacity of soil moisture reservoir (X1) and of the routing reservoir (X3), the time base of a unit hydrograph (X4) and two parameters of the groundwater exchange function $F(X 2$ and $X 5)$. GR5J is combined with a simple snowmelt runoff module using a temperature index (degree day) approach. Snowmelt rate is proportional to the difference between the daily air temperature and the temperature $\mathrm{Tm}$ where melting is initiated. The degree-day factor for melt and the melting temperature are fixed to average values of $3.7 \mathrm{~mm} /{ }^{\circ} \mathrm{C}$ and $0^{\circ} \mathrm{C}$, respectively.

Figure 3. Schematic of the conceptual lumped rainfall-runoff model GR5J (modified by Le Moine 2008).

The Nash-Sutcliffe efficiency criterion NSE (Nash and Sutcliffe 1970) calculated on the square root of the daily discharges $\mathrm{NSE}_{\text {sqrt }}$ (Equation 6) was used as objective function to calibrate the five free parameters while giving less emphasis to extreme high discharges. In addition $\mathrm{NSE}_{\text {Inv }}$ (Equation 7) was also calculated as it gives a special emphasis of very low flows and very little to high flow (Pushpalatha 2013), but was not used for optimisation of the model parameters as this might result in a poorer overall fit. The first two years of available daily catchment rainfall and potential evapotranspiration forcing (generated from 1-km grids and available from 01/01/1961 to 31/12/1962) were used as a spin-up to limit the influence of reservoir initialization on the calibration results. 


$$
N S E_{S Q R T}=1-\frac{\sum_{d=1}^{D}\left(\sqrt{Q_{0}^{d}}-\sqrt{Q_{m}^{d}}\right)^{2}}{\sum_{d=1}^{T}\left(\sqrt{Q_{0}^{d}}-\sqrt{Q_{o}^{d}}\right)^{2}}
$$

$$
\text { Equation } 7 \quad N S E_{I n v}=1-\frac{\sum_{d=1}^{D}\left(\frac{1}{\varepsilon+Q_{0}^{d}}-\frac{1}{\varepsilon+Q_{m}^{d}}\right)^{2}}{\sum_{d=1}^{T}\left(\frac{1}{\varepsilon+Q_{0}^{d}}-\overline{1}\right)^{2} Q_{0}^{d}}
$$

With $Q_{0}^{d}$ observed daily discharge for day $d, Q_{m}^{d}$ simulated daily discharge for day $\mathrm{d}, \bar{X}$ the long term mean of variable $X, D$ the number of days of record and $\varepsilon$ a small operator to avoid division by zero.

$\mathrm{NSE}_{\text {sqrt }}$ calculated over $1963-2011$ is equal to 0.91 and 0.93 for the Thet and Mint catchments respectively, suggesting a good reproduction of the daily variation of flows in both catchments. NSE $E_{\text {Inv }}$ was also calculated so that calibration could be compared with the range of performance of GR5J published for over 1000 French basins (Pushpalatha et al. 2011). The NSE $E_{\text {Inv }}$ of 0.69 and 0.82 found for the Thet and Mint, respectively, are in line with those obtained in the French basins with oceanic climates, where runoff generation is mainly controlled by rainfall and evapotranspiration processes

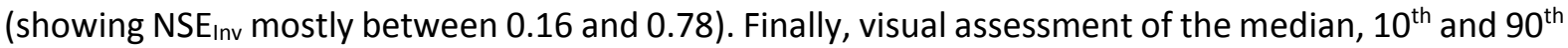
percentile daily hydrograph confirmed the good performance of GR5J (Figure 4). Note the better fit for the Mint than for the Thet where the GR5J model suggests less severe low flow in summer than observations. The day-to-day variability - given by the interdecile range - is correctly reproduced for the Mint whereas an overestimation is noticeable for the Thet particularly in autumn. However in the rest of this paper, results are expressed as changes from GR5J outputs obtained under baseline and 'scenario' conditions, hence removing the effect of any systematic bias in the simulation such as delayed low flow period.

Figure 4. Simulated (red) and observed (black) median annual hydrographs for the Mint at Mint Bridge and the Thet at Bridgham. Shading indicates the interdecile range of the daily discharge for both observations and simulations. Note the log y-axis and the difference in scale

The four hydrological indices were derived from observations and simulations for the period 19632011 (Table 2) and calculated over two distinct periods: all dates with observations within 1963-2011 (Sim /Obs) for comparison with statistics derived from observations (Obs); and complete 1963-2011 period (SimRef) for comparison between catchments. Results show good match between observed and simulated hydrological indicators and absolute relative errors lower than $15 \%$. This suggests that GR5J performs reasonably well, capturing the average pattern of river flows as well as the interannual variability at daily time step.

Table 2. Low flow hydrological indices calculated from all available observations (Obs) and simulated time series (Sim |Obs: for dates with observation available within 1963-2011; Sim Ref: complete 1963 and 2011 period).

\subsection{Climate-low flow response surfaces}

The most comprehensive way to present the sensitivity analysis results is as response surfaces, i.e. hydrological indices associated with the climatic scenarios in a two dimensional space. As a compromise between clarity of the figures versus representation of the complexity of the climate-toflow processes, a 2-dimensional response surface was chosen, with axes represented by the main climate drivers and the colour gradient showing the response of each given hydrological indicator. In Prudhomme et al. (2010) the two axes were defined by the variation of the two parameters of the harmonic function applied to precipitation. However, this representation ignores most of the climatic 
variations described by the methodology, which imposes 12 changes (each scenario has different monthly changes) to three variables ( $\mathrm{P}, \mathrm{T}$ and $\mathrm{PET})$. While a representation of all degrees of freedom would be incomprehensible, the choice of the axes is important as the response surfaces aim to highlight the climatic factors influencing most the low flow regime. Priority was given to include variables directly available from GCMs output, i.e. $P$ and $T$, with changes in PET being implicit from changes in T. Climate elasticity, a measure of the strength of the link between river flow and climate (Schaake 1990, Sankarasubramanian et al. 2001), and linear correlation were also applied between each hydrological index, mean temperature and total precipitation over the four seasons to identify the climate variables with the largest influence on hydrological variability and to inform the choice of the representation as response surfaces. Here the nonparametric elasticity estimator was used:

Equation $8 \quad \varepsilon(X, Y)=\operatorname{median}\left(\frac{X(t y)-\bar{X}}{Y(t y)-\bar{Y}} \overline{\bar{X}}\right)$

where $\varepsilon(X, Y)$ is the elasticity of the variable $X$ to the factor $Y, X(t y)$ and $Y(t y)$ are the values of $X$ and $Y$ for year $t y, N$ is the total number of available years of record, $\bar{X}$ and $\bar{Y}$ are the long term mean values of $X$ and $Y$, respectively. For this application, $X$ is one of the hydrological indices average (Q90, QAS, Q90_dur_5yr, Q90_day_1), $Y$ being precipitation or temperature averaged at different time scales (from month to year).

Finally, bi-linear interpolation of the 1050 scenarios on a given response surfaces was conducted using the function Interpol of the akima R package (Albrecht 2015). The response surfaces are constructed by plotting the hydrological indicator derived from a given climate scenario, the $(x, y)$ coordinates given by the scenarios' climate indicators. Some climate indicators however can have the same value while resulting from different scenarios and annual pathways (e.g. precipitation mean annual change). This means that a same point on the response surface can be associated with different hydrological indicator values. In this case, response surfaces are interpolated based on the minimum, mean and maximum response to capture the range and associated uncertainty in the climate-to-low-flow response. For clarity only the response surfaces based on the mean of all responses are shown in the paper.

\section{Response surfaces and applications}

\subsection{Constructed climate scenario}

Using Equation 1, an ensemble of 35 precipitation scenarios was created associated with mean monthly changes $P_{0}$ ranging from -20 to $+20 \mathrm{~mm}$ and semi-amplitudes $A_{P}$ ranging from 0 to 26.67 $\mathrm{mm} / \mathrm{season}$, all of them by increments of $6.67 \mathrm{~mm} / \mathrm{season}$. The parameter $\varphi_{P}$ was fixed to 1 (minimum in January and maximum in July; Figure 5 right). The majority of scenarios of the framework describe drier, hotter summers (Figure 5); precipitation changes during the transition seasons MAM and SON are evenly distributed while winters are generally wetter. Only a few scenarios are associated with a small cooling.

A set of 30 temperature scenarios was created using Equation 2 to describe mean annual changes $\left(T_{0}+A_{T}\right)$ from $0.5^{\circ} \mathrm{C}$ to $8.5^{\circ} \mathrm{C}$ by increments of $1^{\circ} \mathrm{C}$, with five semi-amplitudes $A_{T}$ ranging from $-0.5^{\circ} \mathrm{C}$ to $3.5^{\circ} \mathrm{C}$ and six values for $T_{0}$ varying from 0 to $5^{\circ} \mathrm{C}$, all of them by increments of $1^{\circ} \mathrm{C}$. The parameter $A_{T}$ takes a negative value when absolute changes are higher in winter than in summer. Minimum and maximum changes occur in February and in August $\left(\varphi_{T}=2\right)$, respectively (Figure 5 , left). 
Changes in precipitation and temperature were combined independently to create a set of 1050 scenarios.

Figure 5. Monthly changes in temperature and precipitation associated with the sensitivity framework scenarios

\subsection{Elasticity and response surfaces}

Elasticity estimates were obtained from an extended dataset of 247 near natural gauged basins in the UK with more than 30 years of flow records, including the Mint and the Thet. The analysis of the elasticity was performed at national scale to identify more clearly the variables to which low flows are sensitive. Climate elasticity was assessed at monthly time scale.

For each basin, monthly elasticities were calculated independently for temperature and precipitation respectively, and the month with the highest absolute value of elasticity was identified for each climate variable. To illustrate the analysis, results are provided for the two hydrological indices Q90 and Q90_day_1. Figure 6 shows for each month the proportion of basins where elasticity for this month is ranked first. Q90 is particularly sensitive to changes in both summer precipitation and temperature: summer climate governs the severity of low flows. On the other hand, for the seasonality index Q90_day_1, the maxima of the two curves are not observed during the same period of the year: Q90_day_1 is most sensitive to changes in spring precipitation but to changes in summer temperature. The differing sensitivity of the two low flow indices highlights that different aspects of low flows are governed by different processes, confirming the complexity of the climate-to-low-flow relationships.

Figure 6. Proportion of basins when absolute value of elasticity of a given month is largest of the year.

The elasticity analysis was complemented by visual examination of response surfaces to identify any discontinuities due to the influence of other factors not represented by the axes of the surfaces. Results show different sensitivity for the indicators and catchments: Q90 is sensitive to spring and summer climate (April to September AMJJAS) in the Mint and to summer and autumn (July to November JJASON) in the Thet. Summer flow (QAS) is also sensitive to spring and summer climate (AMJJAS) in the Mint but to spring climate (March to May MAM) in the Thet. The duration of severe low flow periods is sensitive to summer climate (JJA) in the Mint and autumn (SON) in the Thet. The first day of the low flow period is sensitive to the whole year climate for the Mint and to spring climate (MAM) in the Thet. This demonstrates that the different low flow indices capture different low flow behaviours, each governed by a different climate signal.

Climate-to-low-flow response surfaces for each hydrological index are shown for both catchments in Figure 7; note however the different scales.

Figure 7. Climate-to-low-flow response surfaces of the Mint at Mint Bridge and the Thet at Bridgham with x-axis: precipitation; $y$-axis: temperature. Note the difference in scale and climate drivers associated with each response surface. Reference values (SimRef) are shown as black bar in the key and as a black square on the response surface.

There is a direct link between same season climate and flow changes in the Mint with spring to summer flow QAS showing a clear relationship with spring to summer precipitation and temperature (P-AMJJAS and T-AMJJAS). This is probably because of the low storage in this catchment, meaning that there is little "memory" in the system: QAS decreases with precipitation. It is also notable that additional temperature increase and its associated PET increase can compensate for precipitation 
increase and lead to decrease in QAS; all scenarios with a spring-summer temperature rise of $4^{\circ} \mathrm{C}$ or more are associated with a reduction of QAS even when precipitation increases.

In the Thet, the picture is more complicated: the best climate-to-spring-autumn flow relationship is found with spring precipitation but links with temperature are less smooth, illustrating that climateto-low-flow processes are complex and cannot be captured completely by a 2-dimensional response surface. Unlike the Mint, the Thet has a large groundwater component that delays the climate-to-lowflow response, so changes in spring precipitation have the largest influence on changes in QAS. As the Thet is located in one of the driest regions of England, where actual evapotranspiration is limited by water availability in the soil, an increase in temperature (and by extension, in potential evapotransporation) is not necessarily associated with increase in water losses as evaporation is already limited. As a result, an increase in $\mathrm{P}$ first enhances PET before resulting in flow increase, and increase in $\mathrm{T}$ is only associated with decrease in flow if $\mathrm{P}$ also decreases.

In the Mint, changes in Q90 show a very similar response to climate than QAS, albeit with a slightly stronger signal of decrease (i.e. more scenarios lead to a reduction of Q90 than QAS). In the Thet there is a clearer relationship in the climate-to-low-flow signal for Q90 than for QAS: summer to autumn climate influences most the low flow changes, and there are fewer discontinuities in the response surface (appearing as horizontal graduations in the surfaces and non-uniform relationship between QAS and spring temperature). This suggests that Q90 is mainly controlled by summer and autumn precipitation and temperature signal. Note that relative increase in Q90 are however much larger for the Thet than for the Mint as wetter winters sustain flows all year round, including low flows.

Q90_dur_5yr describes the length of severe continuous low flow periods. Both catchments show an increase in low flow duration for most scenarios but show a very different range of changes, with the Mint showing a maximum increase just above 3 months, against nearly a year for the most extreme scenarios in the Thet. This is likely to reflect a baseflow-dominated signal (see Figure 4) with much smoother hydrograph resulting in uninterrupted periods of low flow.

For the Mint, the date of the first day of low flow is earlier when precipitation decreases or temperature increases by more than $2-3^{\circ} \mathrm{C}$, and later when mean annual precipitation increases. In the Thet, the pattern is similar but with much earlier occurrence possible; for the most extreme scenarios, flow is always lower than baseline Q90 hence first day of occurrence is the $1^{\text {st }}$ January.

\subsection{Response surfaces and mitigation strategies}

One of the strength of the response surfaces is that they can be put into the context of specific weather scenarios. For example this could be during a drought event, where forecast weather anomalies can be considered as future possible range and mapped onto the response surfaces to visualise possible drought trajectories. These trajectories can then be considered when management options are evaluated. Response surfaces could also be used for long term planning under different assumptions of future climate. For example, the Copenhagen Accord recognised that emissions reductions should try to avoid a global temperature rise of more than $2^{\circ} \mathrm{C}$ (UNFCCC 2009); while this does not necessarily correspond to uniform warming across the globe, it is possible to assess the impact of different levels of warming using response surfaces as this might put mitigation strategies into a more local context. Figure 8 shows the range of changes in $Q 90$ associated with a local annual warming ranging from 2.5 to $5.5^{\circ} \mathrm{C}$ for the Mint and the Thet as described by the set of scenarios of 
Figure 5. For both catchments, there is a wide range of responses reflecting the sensitivity of the catchments to the range of precipitation scenarios explored. However, sensitivity to temperature is also visible in the change in the distribution of the response associated with each temperature set. This influence is the largest for the Mint which shows a much stronger decrease in Q90 for the warmest scenarios (black). For the Thet, the influence of temperature is less apparent, mainly shown in the upper tail of the distribution, possibly because evaporative losses do not increase much under warmer climate as they are already water limited. Note that this is an illustrative example as the precipitation scenarios have not been sampled for consistency with climate model projections of given global temperature rise, but they demonstrate how the response surfaces can help in exploring the effect of mitigation policies.

Figure 8. Distribution of changes in Q90 associated with annual warming scenarios for the Mint at Mint Bridge and the Thet at Bridgham.

\subsection{Response surfaces and drought management planning}

Local adaptation planning generally relies on assessing the impact of plausible local climate change scenarios, and response surfaces can help with such assessment by overlaying climate change factors from state-of-the-art climate change projections on the surfaces and identifying the associated responses. Here we used the UKCP09 probabilistic sample climate change factors for the 2050s associated with the medium emission scenario (Murphy et al. 2009). Monthly change factors were extracted for each catchment and combined to be expressed in the same unit as the relevant response surfaces: for the Thet, July to November consistent with the Q90 response surface and for the Mint, June to August consistent with changes in Q90_dur_5yr. Each pair of change factors was displayed on the relevant response surface (Figure 9 top), and the associated change in the low flow indicator quantified and shown as cumulative density function (Figure 9 bottom). Note that the response surface domain for precipitation does not fully capture the variability of the UKCP09 sample, which has a longer tail towards wetter scenarios for both catchments.

Here only the value of climate change factors for the season represented in the response surface was considered and the within-year variability of each UKCP09 scenarios was ignored. This means that the whole annual pathway of some UKCP09 scenarios might be very different from that of the scenarios explored in the sensitivity framework. A more sophisticated method could be used where a sine curve would be fitted to each UKCP09 monthly scenarios and higher likelihood weights given to scenarios closest to those used in the sensitivity framework.

Figure 9. UKCP09 probabilistic samples for the 2050s medium emission (black dots) and climate-low flow response surface and derived risk curves (based on the proportion of UKCP09 scenarios for 2050s time horizon within the explored climatic range) for the Mint a Mint Bridge and the Thet at Bridgham. Response surfaces as described in Figure 7. The risk curves show the percentage of scenarios with changes greater or equal to a response threshold. See text for details.

Similarly to the differences in the catchment climate-to-low-flow responses, the magnitude of possible changes under UKCP09 by the 2050s also shows contrast between the two catchments: assuming all UKCP09 scenarios not plotted on this surface would suggest an increase in the indicator (located on the right-hand side of the curve) and looking again at Q90, the Thet shows a relatively small range of changes, with relatively modest decreases in low flows even under the driest and warmest projections (less than $0.05 \mathrm{~mm}$ decrease; see risk curve in Figure 9), and around $28 \%$ of all UKCP09 scenarios associated with a decrease. However, in the Mint, more of the UKCP09 projections give decreases in 

UKCP09 scenarios within the response surfaces show a decrease, corresponding to a minimum of $46 \%$ of all UKCP09 scenarios (not shown). This may suggest that the Mint is more sensitive to local climate change, and that managers in catchments like this must pay particular attention to the possible impacts on low flows. It also seems clear that the Mint is more vulnerable to UKCP09 changes than the Thet, as a larger proportion of UKCP09 scenarios suggest a decrease of Q90. However it is important to note the range in UKCP09 scenarios, and hence uncertainty associated with the climatic signal, is wider for precipitation in the Mint than in the Thet for the months relevant to low flow processes (as shown by the proportion in UKCP09 scenarios captured by each response surface). As projections of rainfall under climate change are inherently more uncertain than projections of temperature (Shepherd 2014), the response surfaces may show that planning for the Mint is relatively more uncertain than for the Thet.

Looking at a range of different response surfaces also helps to illuminate some of the other conditions for which the water resources manager may need to plan: for example, in the Mint at least $49 \%$ of UKCP09 scenarios suggest an increase in the duration of severe low flow periods (assuming that the $30 \%$ of scenarios outside the response surface all are associated with a decrease) by up to 80 days (Figure 9), while in the Thet the proportion is much smaller but the expected maximum increase will reach 250 days for the most extreme UKCP09 scenario (not shown).

\section{Conclusion}

How do these response surfaces illuminate problems of future water resources and drought management? At the simplest level, they show the different hydrological responses of the contrasting catchments, demonstrated by the different climate drivers associated with the same indicators in the two catchments. In the Mint, representative of typical catchments in Wales and western and northern England, low flows mostly respond to changes in spring and summer rainfall and temperatures while in the Thet, typical of a lowland catchment with limited rainfall and high potential evapotranspiration, the primary climate drivers change with the indicators from spring for first low flow occurrence to summer/autumn for low flow magnitude.

459 It is easy to concentrate on the worst possible outcomes for water resources, but the response surfaces also provide a valuable reminder that the range of possible future climates translates into a wide range of future hydrological conditions. Catchment managers may decide to ignore some of the more favourable outcomes, but in doing so they will be forced explicitly to contemplate their risk tolerance.

It seems that response surfaces are a valuable tool for understanding and communicating the range of possible changes that climate change may bring. However, their use in water resources problems is perhaps less straightforward than in some previous applications such as understanding changes in flood peaks e.g. Prudhomme et al. (2010). Water resources respond not only to the magnitude of changes in rainfall and temperature but also to the timing of these changes; for example, reductions in winter rainfall may be more or less important than equivalent changes in spring, summer or autumn, depending on catchment characteristics. This means that multiple response surfaces are needed to explain the range of possible changes. Identifying and then interpreting these response surfaces is far 
472 from trivial. Inappropriate identification of response surfaces could lead to poor adaptation response,

473 with a risk of misplaced confidence in inadequate interventions.

474 In addition, the choice and pattern of the climate scenarios explored in the sensitivity framework have 475 also an influence on the result. Here, consistently with most future climate-change signals, a simple 476 cosine function was used to describe a seasonal change in the climatology, which fixes the seasons of 477 maxima and minima. Different seasonal patterns, or more complex variability in the seasonal changes 478 of precipitation and temperature, would influence the response surfaces but also greatly add in 479 complexity to both their representation and interpretation. One important limitation of the 480 methodology is its inevitable simplification of complex processes, and its function as a screening tool 481 rather than as a comprehensive process-based impact analysis.

482 Finally, for response surfaces to be of full value to water resources managers, the managers 483 themselves will need to invest time in investigating and understanding water resources system 484 response. While this is unlikely to be wasted effort, it does mean that managers need to be involved 485 early in a project, which may not always be welcome to busy managers facing other, more immediate 486 pressures.

487 This paper demonstrates that the scenario-neutral approach can be of great value in understanding 488 future pressures on water resources. The response surfaces developed here look only at hydrological 489 response and hence possible impacts of climate change, but the concept could be developed further 490 in various directions. One simple development would be to work with catchment managers to identify 491 regions of the response surface that would either cause different levels of impact or demand different 492 types of response. Fung et al. (2013) demonstrated this with a simple matrix of changes in the duration 493 and magnitude of low flows, looking at the possible impact on ecosystem form and function in a chalk 494 catchment in southern England. Their matrix was a simple grid; on a response surface, it would be 495 possible to identify different regions of irregular shape, making the response surface approach much 496 more flexible. It may also be possible to identify thresholds beyond which change would demand 497 alternative approaches to management, and also which climate drivers would result in the threshold 498 being crossed. Such thresholds could include regulatory thresholds, such as abstraction licence 499 conditions or discharge consents. It may also be valuable to develop response surfaces that reflect 500 variables that are of more direct relevance to water resources managers, such as reservoir deployable 501 output. This could be valuable in planning climate change adaptation interventions, though every time 502 the water supply system changes the response surface would also change and need to be recalculated, 503 negating some of the benefits of the response surface approach. However, exploring these concepts 504 further could add to the benefits of scenario-neutral approaches and improve the flexibility of 505 approaches to climate change adaptation.

\section{5. Acknowledgements}

507 Christel Prudhomme was funded by NERC-Water Resource Science Area National Capability. Funding 508 for Eric Sauquet was provided by a grant from la Region Rhône-Alpes. The views expressed in this 509 paper are those of the authors alone and not of the organisations for which they work. The authors 510 thank three anonymous reviewers for their suggestions to improve the manuscript. 
512

Albrecht, G. (2015). Package 'akima'. Interpolation of irregularly spaced data. Package r. Version 0.5.11.

Brown, C., Ghile, Y., Laverty, M. \& Li, K. (2012). Decision scaling: Linking bottom-up vulnerability analysis with climate projections in the water sector. Water Resources Research, 48: W09537.

Brown, C., Werick, W., Leger, W. \& Fay, D. (2011). A decision-analytic approach to managing climate risks: Application to the upper great lakes. JAWRA Journal of the American Water Resources Association, 47: 524-534.

Ekström, M., Grose, M. R. \& Whetton, P. H. (2015). An appraisal of downscaling methods used in climate change research. Wiley Interdisciplinary Reviews: Climate Change, 6: 301-319.

Folland, C. K., Hannaford, J., Bloomfield, J. P., Kendon, M., Svensson, C., Marchant, B. P., Prior, J. \& Wallace, E. (2014). Multi-annual droughts in the english lowlands: A review of their characteristics and climate drivers in the winter half year. Hydrol. Earth Syst. Sci. Discuss., 11: 12933-12985.

Fung, F., Watts, G., Lopez, A., Orr, H., New, M. \& Extence, C. (2013). Using large climate ensembles to plan for the hydrological impact of climate change in the freshwater environment. Water Resources Management, 27: 1063-1084.

Gluckman, P. (2014). Policy: The art of science advice to government. Nature, 507: 163-165.

Gustard, A., Bullock, A. \& Dixon, J. M. (1992). Low flow estimation in the united kingdom. In: HYDROLOGY, I. O. (ed.). Wallingford: Institute of Hydrology Report 108.

Jones, P. D., Lister, D. H., Wilby, R. L. \& Kostopoulou, E. (2006). Extended riverflow reconstructions for england and wales, 1865-2002. International Journal of Climatology, 26: 219-231.

Kallis, G. (2008). Droughts. Annual Review of Environment and Resources, 33: 85-118.

Keller, V. D. J., Tanguy, M., Prosdocimi, I., Terry, J. A., Hitt, O., Cole, S. J., Fry, M., Morris, D. G. \& Dixon, H. (2015). Ceh-gear: $1 \mathrm{~km}$ resolution daily and monthly areal rainfall estimates for the uk for hydrological use. Earth Syst. Sci. Data Discuss., 8: 83-112.

Le Moine, N. (2008). Le bassin versant de surface vu par le souterrain : Une voie d'amélioration des performances et du réalisme des modèles pluie-débit ? PhD - Doctorat Géosciences et Ressources Naturelles PhD, Université Pierre et Marie Curie Paris VI.

Lempert, R. J., Groves, D. G., Popper, S. W. \& Bankes, S. C. (2006). A general, analytic method for generating robust strategies and narrative scenarios. Management Science, 52: 514-528.

Lloyd-Hughes, B. (2014). The impracticality of a universal drought definition. Theoretical and Applied Climatology, 117: 607-611.

Marsh, T., Cole, G. \& Wilby, R. (2007). Major droughts in england and wales, 1800-2006. Weather, 62: 87-93.

Murphy, J. M., Sexton, D. M. H., Jenkins, G. J., Booth, B. B. B., Brown, C. C., Clark, R. T., Collins, M., Harris, G. R., Kendon, E. J., Betts, R. A., Brown, S. J., Humphrey, K. A., Mccarthy, M. P., Mcdonald, R. E., Stephens, A., Wallace, C., Warren, R., Wilby, R. \& Wood, R. A. (2009). Uk climate projections science report: Climate change projections. Exeter, UK: Met Office Hadley Centre.

Nash, J. E. \& Sutcliffe, J. V. (1970). River flow forecasting through conceptual models part i -- a discussion of principles. Journal of Hydrology, 10: 282-290.

Oudin, L., Hervieu, F., Michel, C., Perrin, C., Andréassian, V., Anctil, F. \& Loumagne, C. (2005). Which potential evapotranspiration input for a lumped rainfall-runoff model?: Part 2-towards a simple and efficient potential evapotranspiration model for rainfall-runoff modelling. Journal of Hydrology, 303: 290-306.

Parry, S., Hannaford, J., Lloyd-Hughes, B. \& Prudhomme, C. (2012). Multi-year droughts in europe: Analysis of development and causes. Hydrology Research, 43: 689-706.

Perrin, C., Michel, C. \& Andréassian, V. (2003). Improvement of a parsimonious model for streamflow simulation. Journal of Hydrology, 279: 275-289. 
Perry, M., Hollis, D. \& Elms, M. (2009). The generation of daily gridded datasets of temperature and rainfall for the uk. Climate memorandum No 24. Exeter: National Climate Information Centre, Met Office.

Prudhomme, C., Giuntoli, I., Robinson, E. L., Clark, D. B., Arnell, N. W., Dankers, R., Fekete, B. M., Franssen, W., Gerten, D., Gosling, S. N., Hagemann, S., Hannah, D. M., Kim, H., Masaki, Y., Satoh, Y., Stacke, T., Wada, Y. \& Wisser, D. (2014). Hydrological droughts in the 21st century, hotspots and uncertainties from a global multimodel ensemble experiment. Proceedings of the National Academy of Sciences, 111: 3262-3267.

Prudhomme, C., Kay, A., Crooks, S. \& Reynard, N. (2013). Climate change and river flooding: Part 2 sensitivity characterisation for british catchments and example vulnerability assessments. Climatic Change, 119: 949-964.

Prudhomme, C., Wilby, L. R., Crooks, S. M., Kay, A. L. \& Reynard, N. S. (2010). Scenario-neutral approach to climate change impact studies: Application to flood risk. Journal of Hydrology, 390: 198-209.

Prudhomme, C., Young, A., Watts, G., Haxton, T., Crooks, S., Williamson, J., Davies, H., Dadson, S. \& Allen, S. (2012). The drying up of britain? A national estimate of changes in seasonal river flows from 11 regional climate model simulations. Hydrological Processes, 26: 1115-1118.

Pushpalatha, R. (2013). Low-flow simulation and forecasting on french river basins: A hydrological modelling approach. PhD, AgroParis Tech.

Pushpalatha, R., Perrin, C., Le Moine, N., Mathevet, T. \& Andréassian, V. (2011). A downward structural sensitivity analysis of hydrological models to improve low-flow simulation. Journal of Hydrology, 411: 66-76.

Sankarasubramanian, A., Vogel, R. M. \& Limbrunner, J. F. (2001). Climate elasticity of streamflow in the united states. Water Resources Research, 37: 1771-1781.

Schaake, J. C. (1990). From climate to flow. In: WAGGONER, P. E. (ed.) Climate change and u.S. Water resources. John Wiley \& Sons.

Seiller, G., Hajji, I. \& Anctil, F. (2015). Improving the temporal transposability of lumped hydrological models on twenty diversified u.S. Watersheds. Journal of Hydrology: Regional Studies, 3: 379399.

Shepherd, T. G. (2014). Atmospheric circulation as a source of uncertainty in climate change projections. Nature Geoscience, 7: 703-708.

Sofoulis, Z. (2005). Big water, everyday water: A sociotechnical perspective. Continuum, 19: 445-463.

Spraggs, G., Peaver, L., Jones, P. \& Ede, P. (2015). Re-construction of historic drought in the anglian region (uk) over the period 1798-2010 and the implications for water resources and drought management. Journal of Hydrology, 526: 231-252.

Stocker, T. F., Qin, D., Plattner, G.-K., Alexander, L. V., Allen, S. K., Bindoff, N. L., BréOn, F.-M., Church, J. A., Cubasch, U., Emori, S., Forster, P., Friedlingstein, P., Gillett, N., Gregory, J. M., Hartmann, D. L., Jansen, E., Kirtman, B., Knutti, R., Krishna kumar, K., Lemke, P., Marotzke, J., MassonDelmotte, V., Meehl, G. A., Mokhov, I. I., Piao, S., Ramaswamy, V., Randall, D., Rhein, M., Rojas, M., Sabine, C., Shindell, D., Talley, L. D., Vaughan, D. G. \& Xie, S.-P. (2013). Technical summary. In: STOCKER, T. F., QIN, D., PLATTNER, G.-K., TIGNOR, M., ALLEN, S. K., BOSCHUNG, J., NAUELS, A., XIA, Y., BEX, V. \& MIDGLEY, P. M. (eds.) Climate change 2013: The physical science basis. Contribution of working group $i$ to the fifth assessment report of the intergovernmental panel on climate change. Cambridge, United Kingdom and New York, NY, USA: Cambridge University Press.

Tallaksen, L. M. \& Van Lanen, H. a. J. (eds.) (2004). Hydrological drought - processes and estimation methods for streamflow and groundwater: Elsevier.

Tanguy, M., Dixon, H., Prosdocimi, I., Morris, D. G. \& Keller, V. D. J. (2014). Gridded estimates of daily and monthly areal rainfall for the united kingdom (1890-2012) [ceh-gear]. NERC Environmental Information Data Centre. 
Terray, L. \& Boé, J. (2013). Quantifying 21st-century france climate change and related uncertainties. Comptes Rendus Geoscience, 345: 136-149.

Thompson, N., Barrie, I. A. \& Ayles, M. (1982). The meteorological office rainfall and evaporation calculation system: Morecs (july 1981). Hydrological Memorandum N 45. Bracknell, UK: Met. Office.

Tian, Y., Xu, Y.-P. \& Zhang, X.-J. (2013). Assessment of climate change impacts on river high flows through comparative use of gr $4 \mathrm{j}$, hbv and xinanjiang models. Water Resources Management, 27: 2871-2888.

Touma, D., Ashfaq, M., Nayak, M. A., Kao, S.-C. \& Diffenbaugh, N. S. (2015). A multi-model and multiindex evaluation of drought characteristics in the 21st century. Journal of Hydrology, 526: 196207.

Unfccc (2009). Copenhagen accord. Fccc/cp/2009/I.7.

Vidal, J. P., Martin, E., Kitova, N., Najac, J. \& Soubeyroux, J. M. (2012). Evolution of spatio-temporal drought characteristics: Validation, projections and effect of adaptation scenarios. Hydrology and Earth System Sciences, 16: 2935-2955.

Watts, G., Christierson, B. V., Hannaford, J. \& Lonsdale, K. (2012). Testing the resilience of water supply systems to long droughts. Journal of Hydrology, 414-415: 255-267.

Weisheimer, A. \& Palmer, T. N. (2014). On the reliability of seasonal climate forecasts. Journal of The Royal Society Interface, 11.

Weiß, M. (2011). Future water availability in selected european catchments: A probabilistic assessment of seasonal flows under the ipcc a1b emission scenario using response surfaces. Natural Hazards and Earth System Sciences, 11: 2163-2171.

Wetterhall, F., Graham, L. P., Andréasson, J., Rosberg, J. \& Yang, W. (2011). Using ensemble climate projections to assess probabilistic hydrological change in the nordic region. Natural Hazards and Earth System Sciences, 11: 2295-2306.

Whateley, S., Steinschneider, S. \& Brown, C. (2014). A climate change range-based method for estimating robustness for water resources supply. Water Resources Research, 50: 8944-8961.

Wilby, R. L. \& Dessai, S. (2010). Robust adaptation to climate change. Weather, 65: 180-185.

Wilhite, D., Svoboda, M. \& Hayes, M. (2007). Understanding the complex impacts of drought: A key to enhancing drought mitigation and preparedness. Water Resources Management, 21: 763-774.

Wilks, D. S. 2006. Statistical methods in the atmospheric science, Elsevier.

Wu, W., Clark, J. S. \& Vose, J. M. (2014). Response of hydrology to climate change in the southern appalachian mountains using bayesian inference. Hydrological Processes, 28: 1616-1626.

Zhang, Y., Vaze, J., Chiew, F. H. S., Teng, J. \& Li, M. (2014). Predicting hydrological signatures in ungauged catchments using spatial interpolation, index model, and rainfall-runoff modelling. Journal of Hydrology, 517: 936-948.

\section{Appendix - Hydrological indices calculations}

\subsection{Daily flow exceeded $90 \%$ of the time Q90}

The $10^{\text {th }}$ percentile daily flow calculated over the relevant period.

\subsection{Mean flow April to September QAS}

The average daily flow between 1 April and 30 September.

\subsection{Duration of severe low flow episodes Q90_dur_5yr}

First the maximum duration of consecutive flows Q under Q90 for each water year (Q90_dur) was sampled by block maxima approach. Q90_dur_5yr is then defined as the empirical $80^{\text {th }}$ percentile of 
655

656

657

658

659

660

661

662

663

664

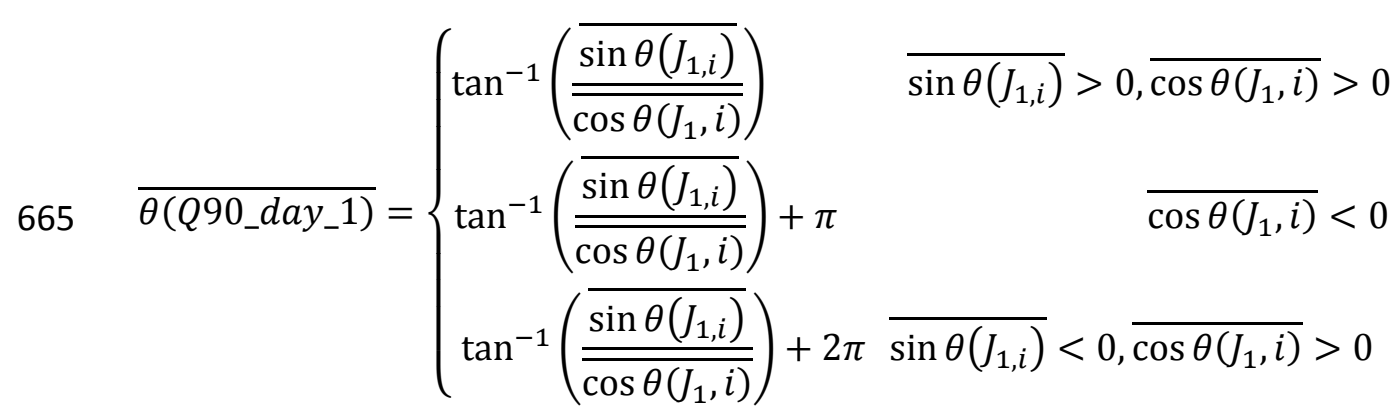

cumulative distribution function of Q90_dur. A non-parametric approach is used to estimate the quantile with a return period of 5 years since there is no guarantee that a distribution valid under current climate may still hold under climate change.

\subsection{Day of first occurrence of low flow Q90_day_1}

The procedure is as follow:

1. Identify $J_{1, i}$ first day with flow $Q$ below $Q 90$ for water year $i$, in Julian day;

2. Convert $J_{1, i}$ into angle, in radian, by $\theta\left(J_{1, i}\right)=\frac{2 \pi}{365} J_{1, i}$;

3. Calculate mean of cosines and sines of each angle (years without flow below Q90 not accounted for);

4. Calculate associated angle as

666 5. Convert back into a date, in Julian day, by $Q 90 \_d a y \_1=\frac{365}{2 \pi} \overline{\theta\left(Q 90 \_d a y \_1\right)}$; 
1 Low flow response surfaces for drought decision support: a case study from the UK

2

3 Christel Prudhomme* ${ }^{* 1,2}$, Eric Sauquet ${ }^{3,1}$, Glenn Watts ${ }^{4,5}$

4 1. Centre for Ecology and Hydrology, Wallingford, OX10 8BB, UK

5 2. Department of Geography, Loughborough University, LE11 3TU, UK

6 3. IRSTEA, UR HHLY, Hydrology-Hydraulics, 5 rue de la Doua CS70077, F-69626 VILLEURBANNE cedex, 7 France

8 4. Evidence Directorate, Environment Agency, Deanery Road, Bristol, BS1 5AH, UK

9 5. Department of Geography, King's College London, London WC2R 2LS

10

11 Corresponding author: Christel Prudhomme (email: chrp@ceh.ac.uk)

12

13 Tables captions

14

15 Table 1. Main characteristics of the two basins. Statistics are computed on records available within the period 01/01/1961 16 to 31/12/2011 (1: from http://www.ceh.ac.uk/data/nrfa/index.html)

17 Table 2. Low flow hydrological indices calculated from all available observations (Obs) and simulated time series (Sim /Obs: 18 for dates with observation available within 1963-2011; Sim Ref: complete 1963 and 2011 period). 


\begin{tabular}{|c|c|c|}
\hline & Mint at Mint bridge 73011 & Thet at Bridgham 33044 \\
\hline Area $\left(\mathrm{km}^{2}\right)$ & 65.8 & 277.8 \\
\hline Median elevation (m) & 209.3 & 39.2 \\
\hline Catchment description ${ }^{1}$ & $\begin{array}{l}\text { Geology: Steep, very wet } \\
\text { catchment. Predominantly } \\
\text { impervious Silurian slate with } \\
\text { bands of flags and shale, small } \\
\text { patches of Carboniferous } \\
\text { Limestone and basal } \\
\text { conglomerate, patchy Boulder } \\
\text { Clay cover in middle and lower } \\
\text { reaches. } \\
\text { Land use: Sheep grazing with } \\
\text { peat moorland in extreme } \\
\text { north. }\end{array}$ & $\begin{array}{l}\text { Geology: Chalk with } \\
\text { approximately } 75 \% \text { boulder clay } \\
\text { cover. } \\
\text { Land use: arable with some } \\
\text { forest and grassland, several } \\
\text { small towns }\end{array}$ \\
\hline Record period & 01/08/1970-30/09/2013 & 01/06/1967-30/09/2013 \\
\hline $\begin{array}{l}\text { Mean annual } \\
\text { precipitation }(\mathrm{mm})\end{array}$ & 1585 & 636 \\
\hline $\begin{array}{l}\text { Mean annual } \\
\text { temperature }\left({ }^{\circ} \mathrm{C}\right)\end{array}$ & 8.1 & 9.7 \\
\hline $\begin{array}{l}\text { Mean annual potential } \\
\text { evapotranspiration } \\
(\mathrm{mm})\end{array}$ & 479 & 630 \\
\hline $\begin{array}{l}\text { Mean annual runoff } \\
(\mathrm{mm})\end{array}$ & 1197 & 186 \\
\hline Base Flow Index & 0.31 & 0.74 \\
\hline Factors affecting runoff $^{1}$ & $\begin{array}{l}\text { Natural to within } 10 \% \text { at the } 95 \\
\text { percentile flow }\end{array}$ & $\begin{array}{l}\text { Groundwater abstraction } \\
\text { and/or recharge, effluent } \\
\text { returns and industrial and/or } \\
\text { agricultural abstraction }\end{array}$ \\
\hline
\end{tabular}




\begin{tabular}{ccccccc|}
\hline & \multicolumn{3}{c}{ Mint at Mint bridge 73011 } & \multicolumn{3}{c|}{ Thet at Bridgham 33044 } \\
\hline & Obs & Sim/Obs & Sim Ref & Obs & Sim |Obs & Sim Ref \\
\hline Q90 mm/day & 0.386 & 0.438 & 0.466 & 0.141 & 0.135 & 0.137 \\
(m3/s) & 0.294 & 0.334 & 0.355 & 0.453 & 0.434 & 0.440 \\
QAS (mm/day) & 1.858 & 1.740 & 1.828 & 0.344 & 0.354 & 0.354 \\
(m3/s) & 1.415 & 1.325 & 1.392 & 1.105 & 1.137 & 1.139 \\
\hline Q90_dur_5yr (day) & 29 & 35 & 41.4 & 34.8 & 41.8 & 44.6 \\
Q90_day_1 (Julian day) & 158 & 155 & 146 & 196 & 226 & 225 \\
(date) & 7th June & 4th June & 26th May & 15th July & 14th Aug. & 13th Aug. \\
\hline
\end{tabular}

Table 2. Low flow hydrological indices calculated from all available observations (Obs) and simulated time series (Sim | Obs: for dates with observation available within 1963-2011; Sim Ref: complete 1963 and 2011 period). 
Figure

Click here to download Figure: Fig1_JOEE_July2015.png

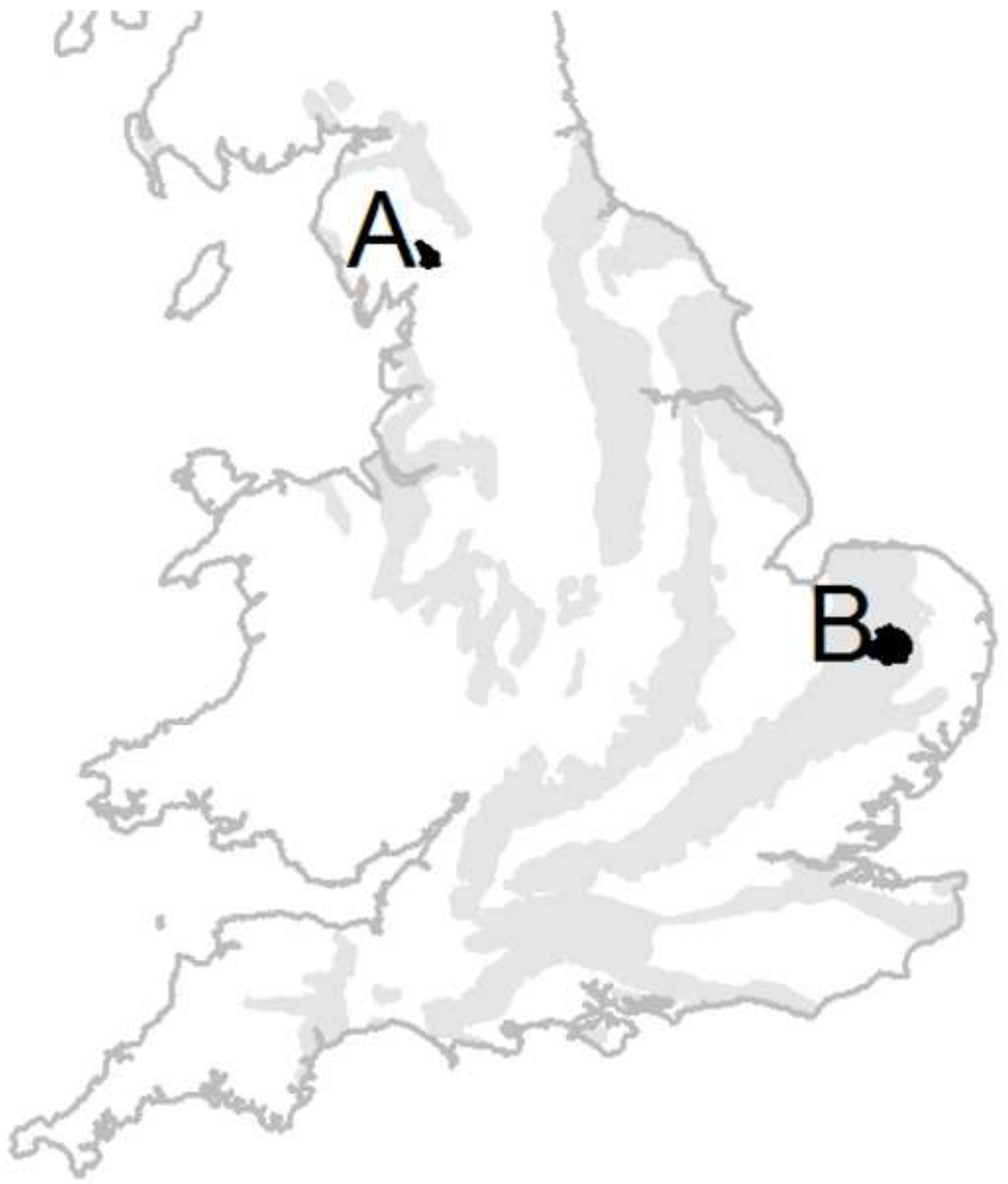




\section{Mint at Mint Bridge}

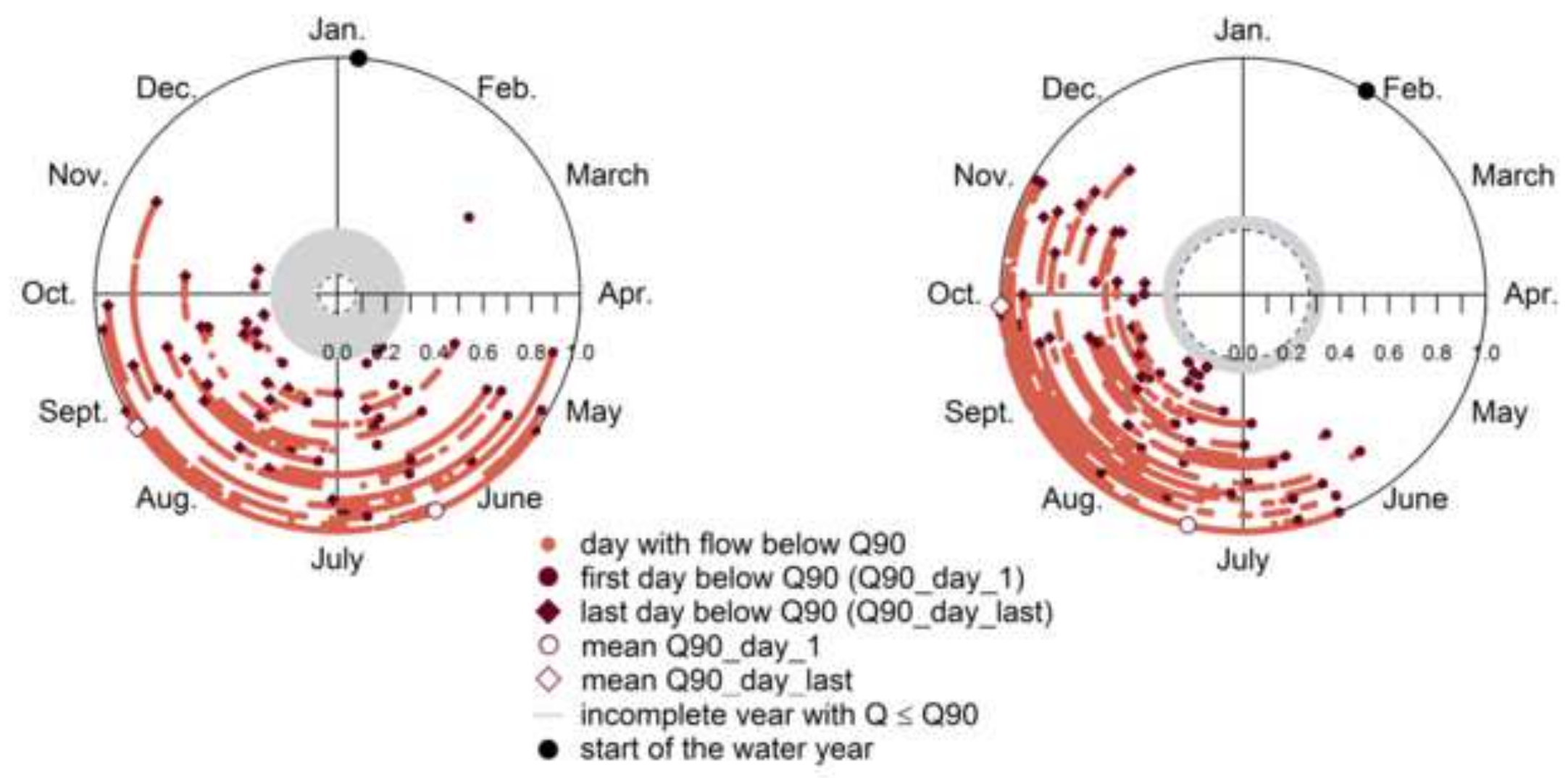

Thet at Bridgham

- day with flow below Q90

last day below $\mathrm{Q} 90$ (Q90 day last)

incomplete vear with $Q \leq Q 90$

- start of the water year 


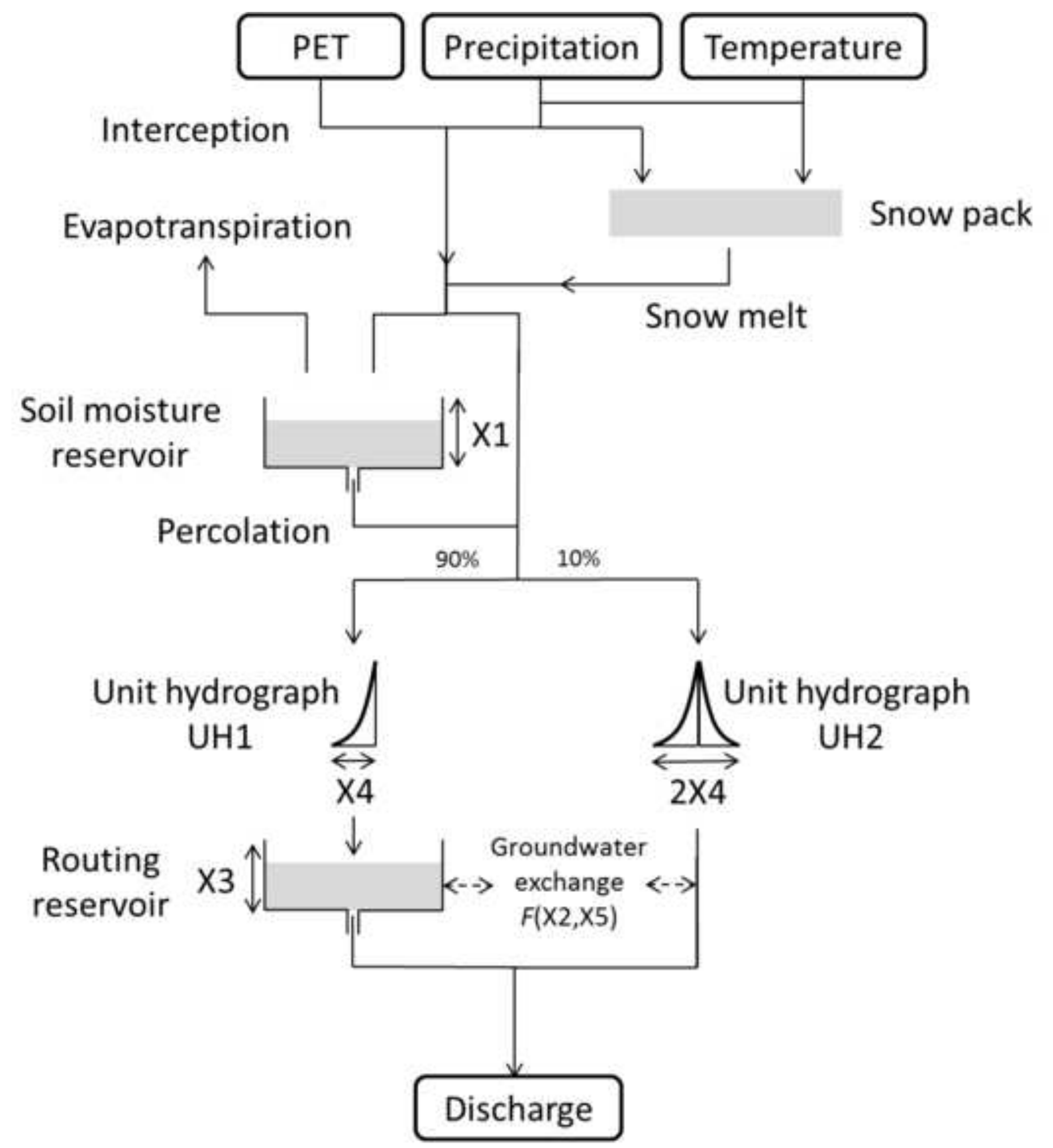


Mint at Mint Bridge

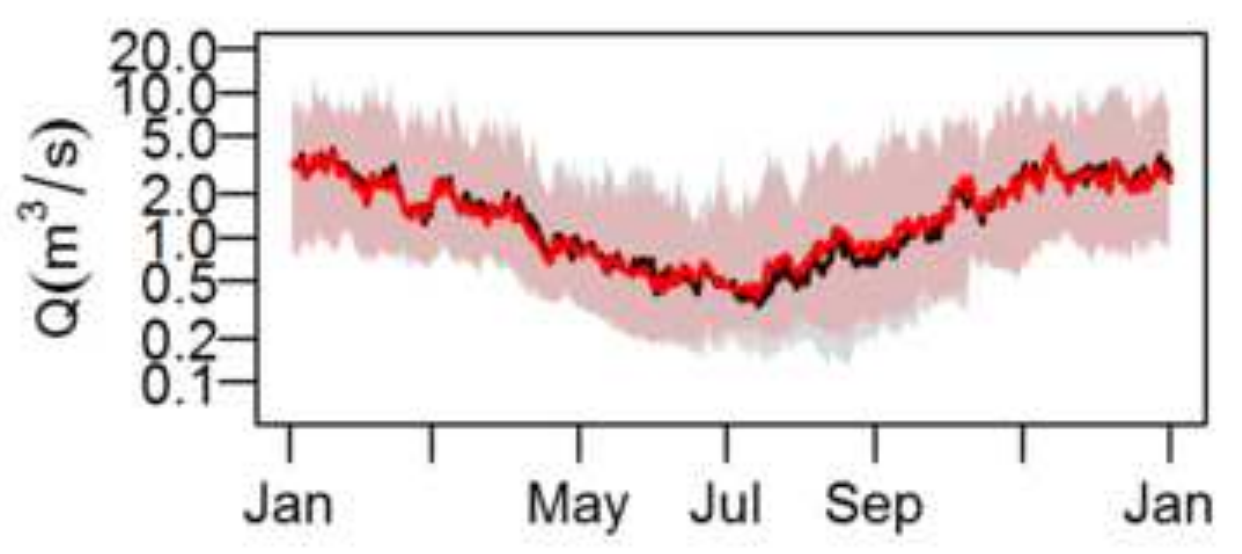

\section{Thet at Bridgham}

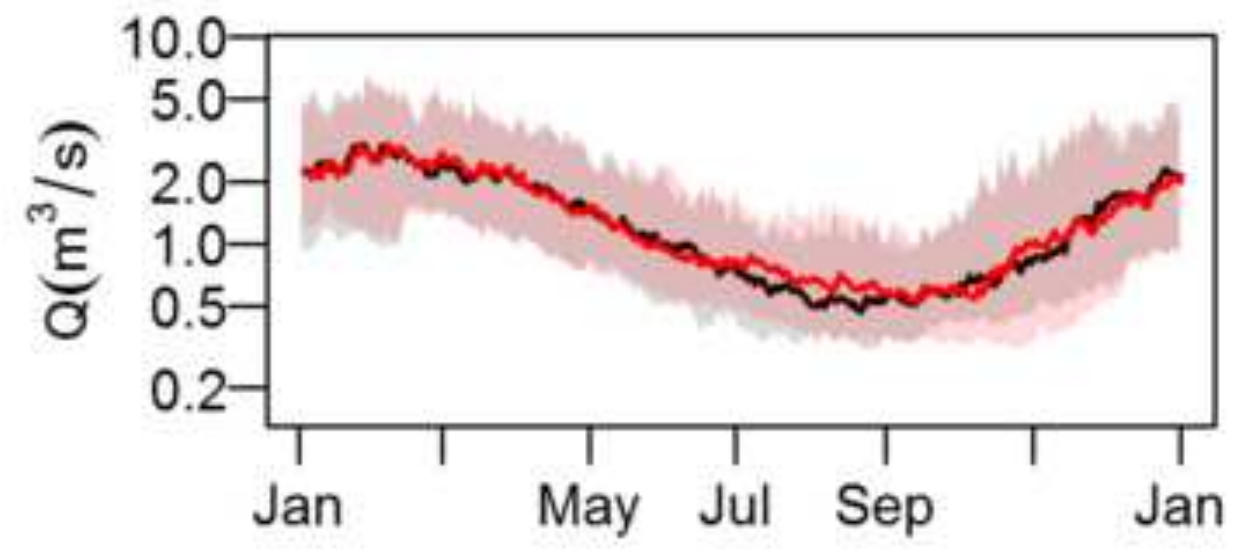




\section{Temperature}

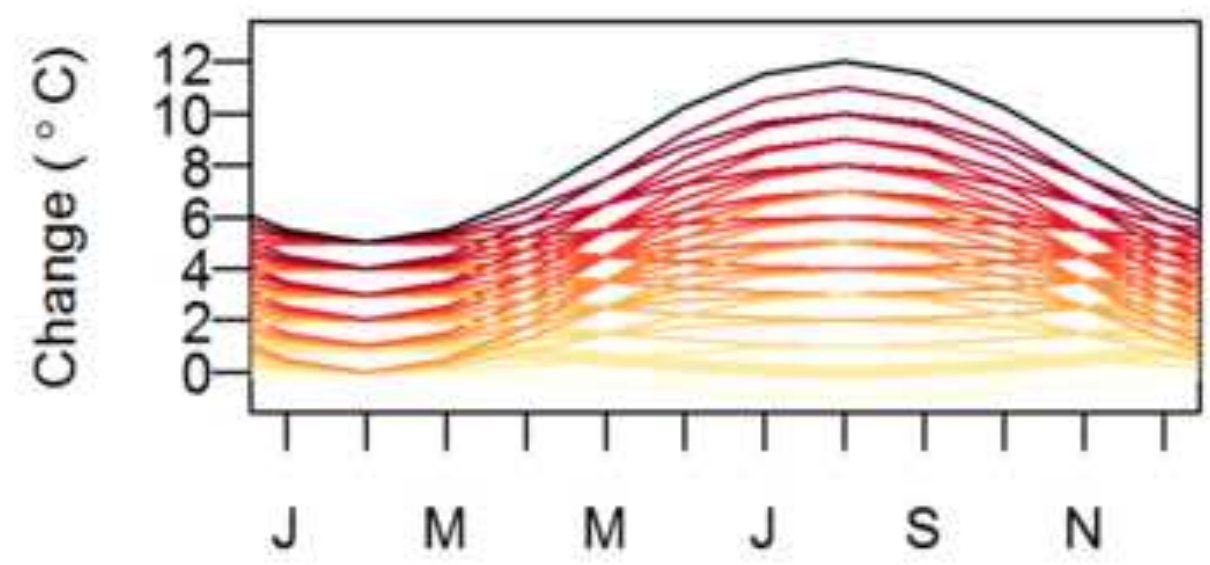

\section{Precipitation}

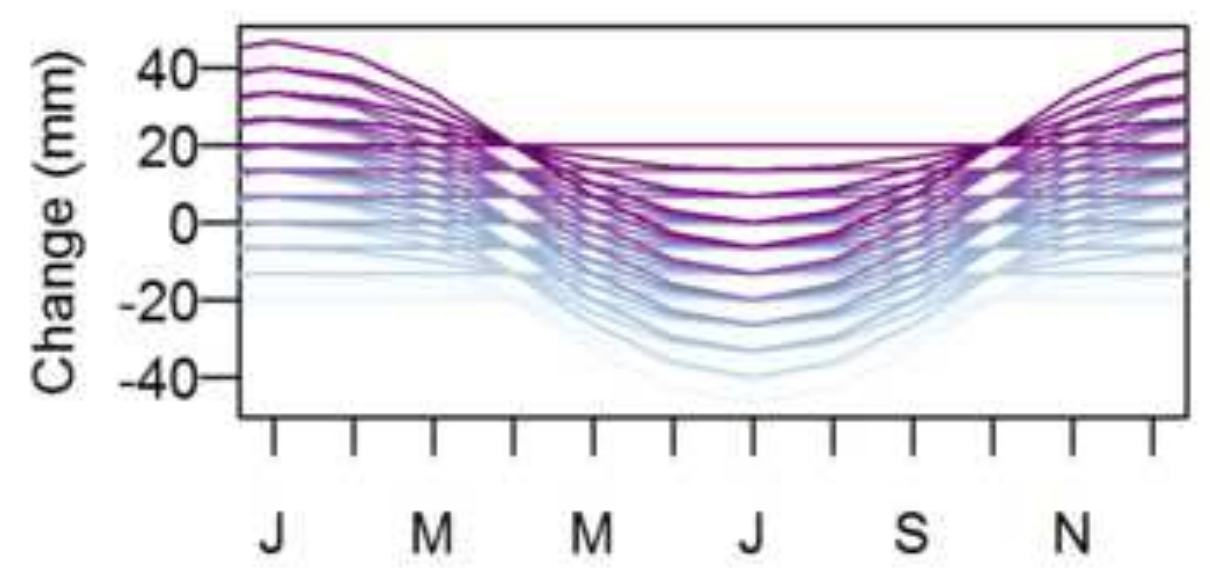



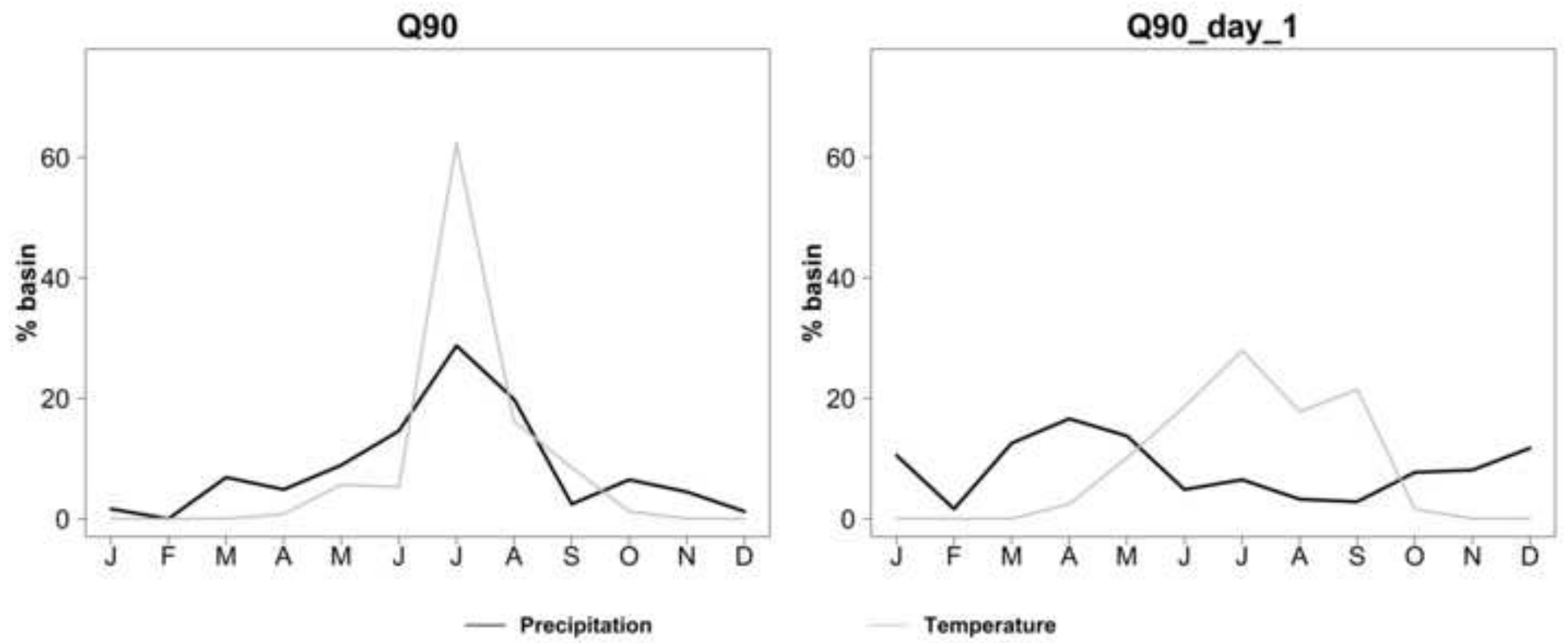
Mint at Mint Bridge

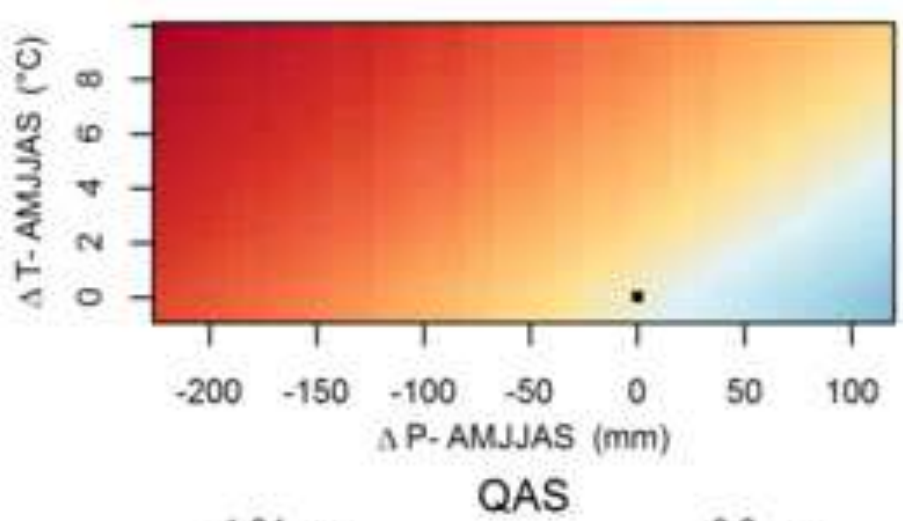

$-1.34 \mathrm{~mm}$
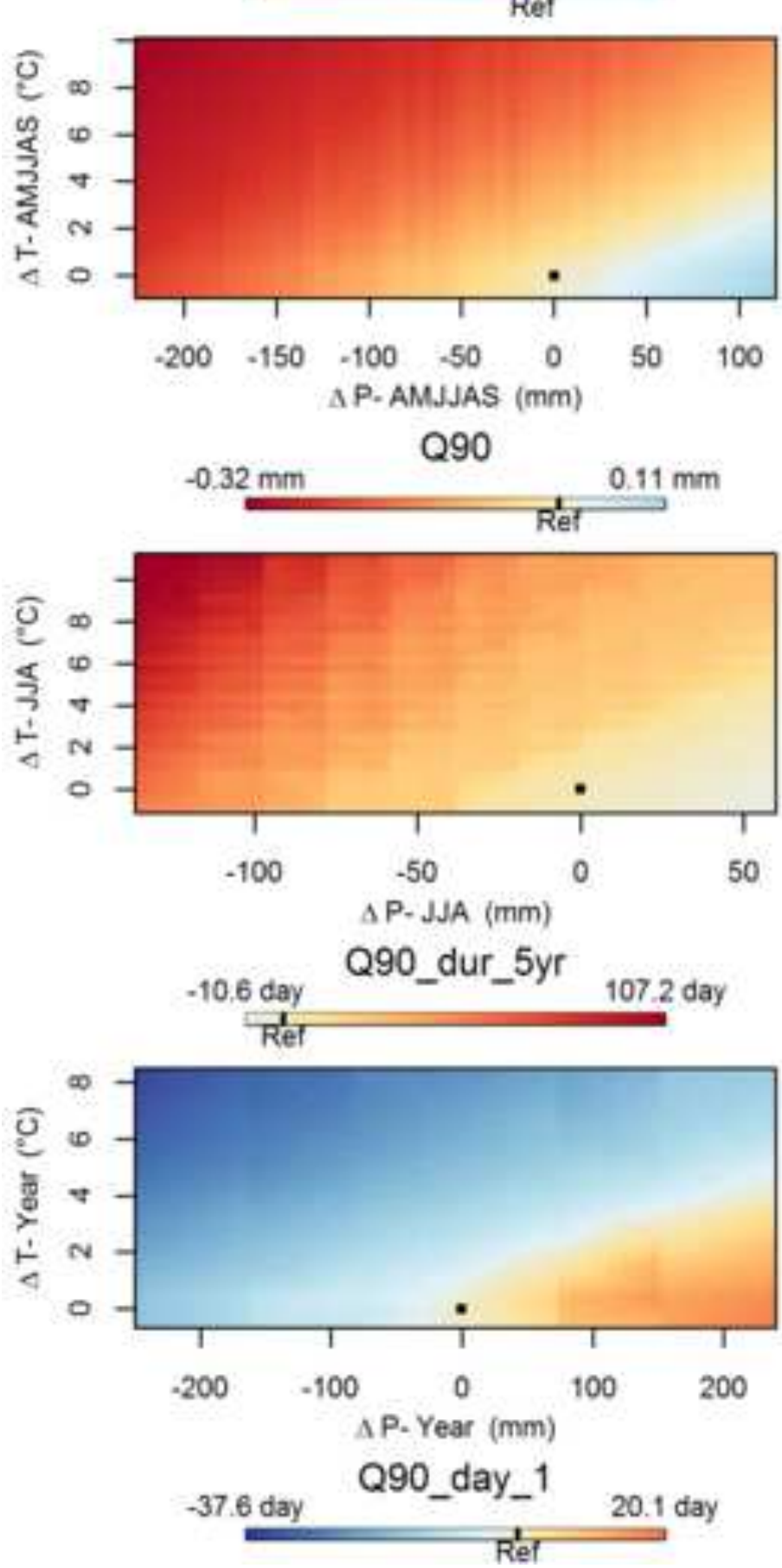

Thet at Bridgham
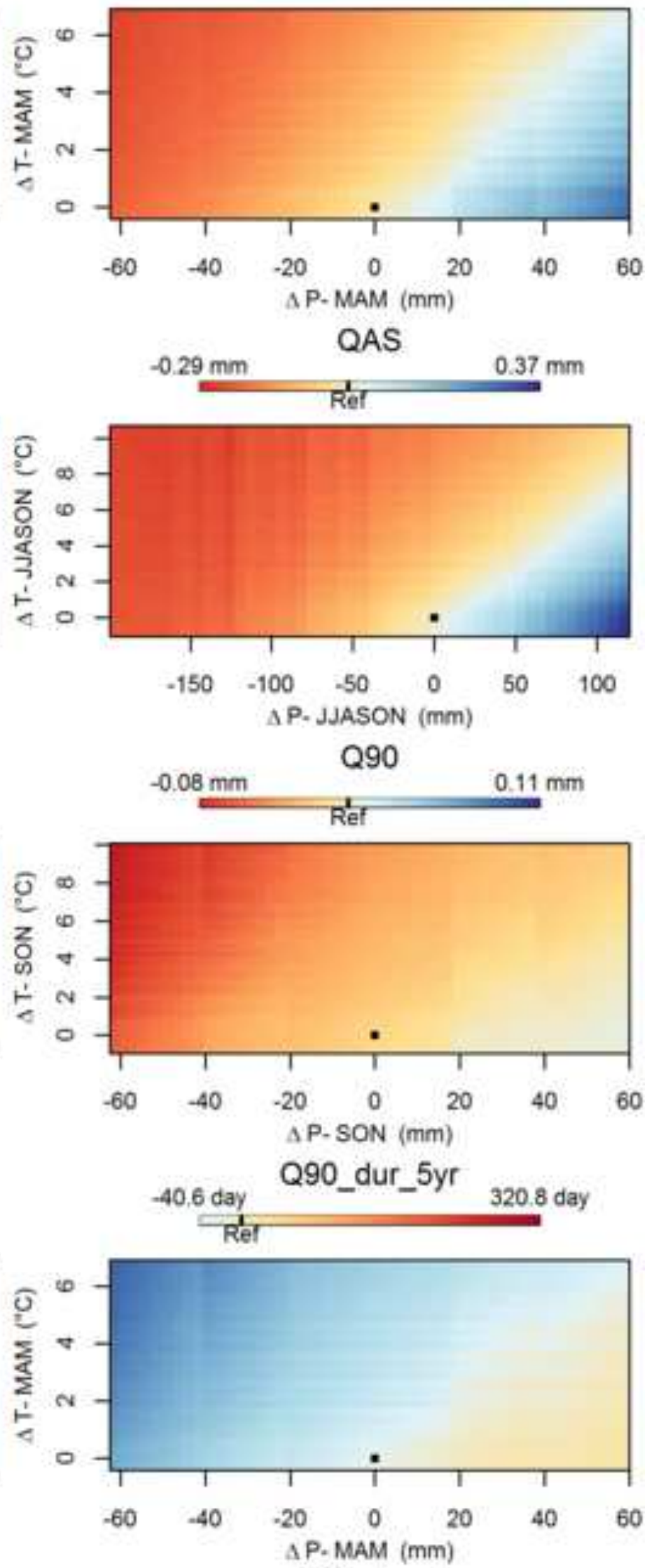

-205.8 day
Q90_day_1 10.6 day 

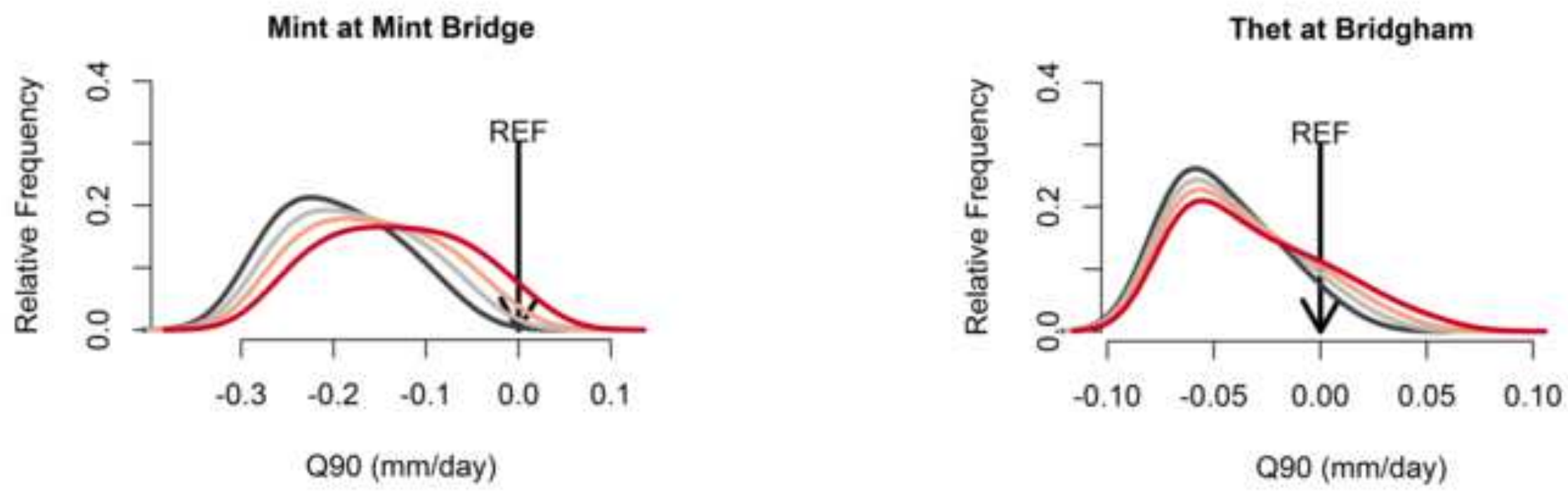

$-+2.5^{\circ} \mathrm{C}-+3.5^{\circ} \mathrm{C}-+4.5^{\circ} \mathrm{C}-+5.5^{\circ} \mathrm{C}$ 


\section{Mint at Mint Bridge}
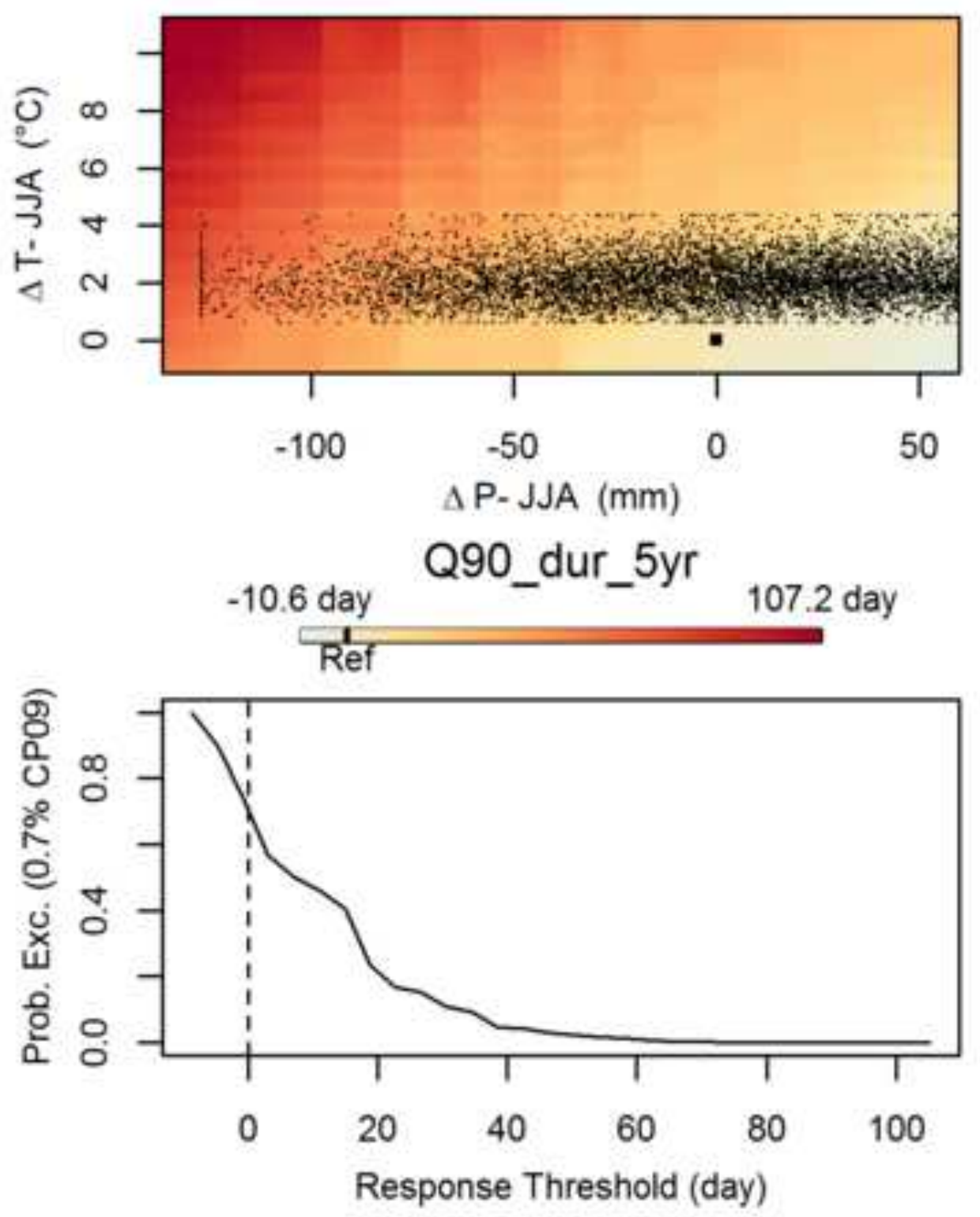

\section{Thet at Bridgham}
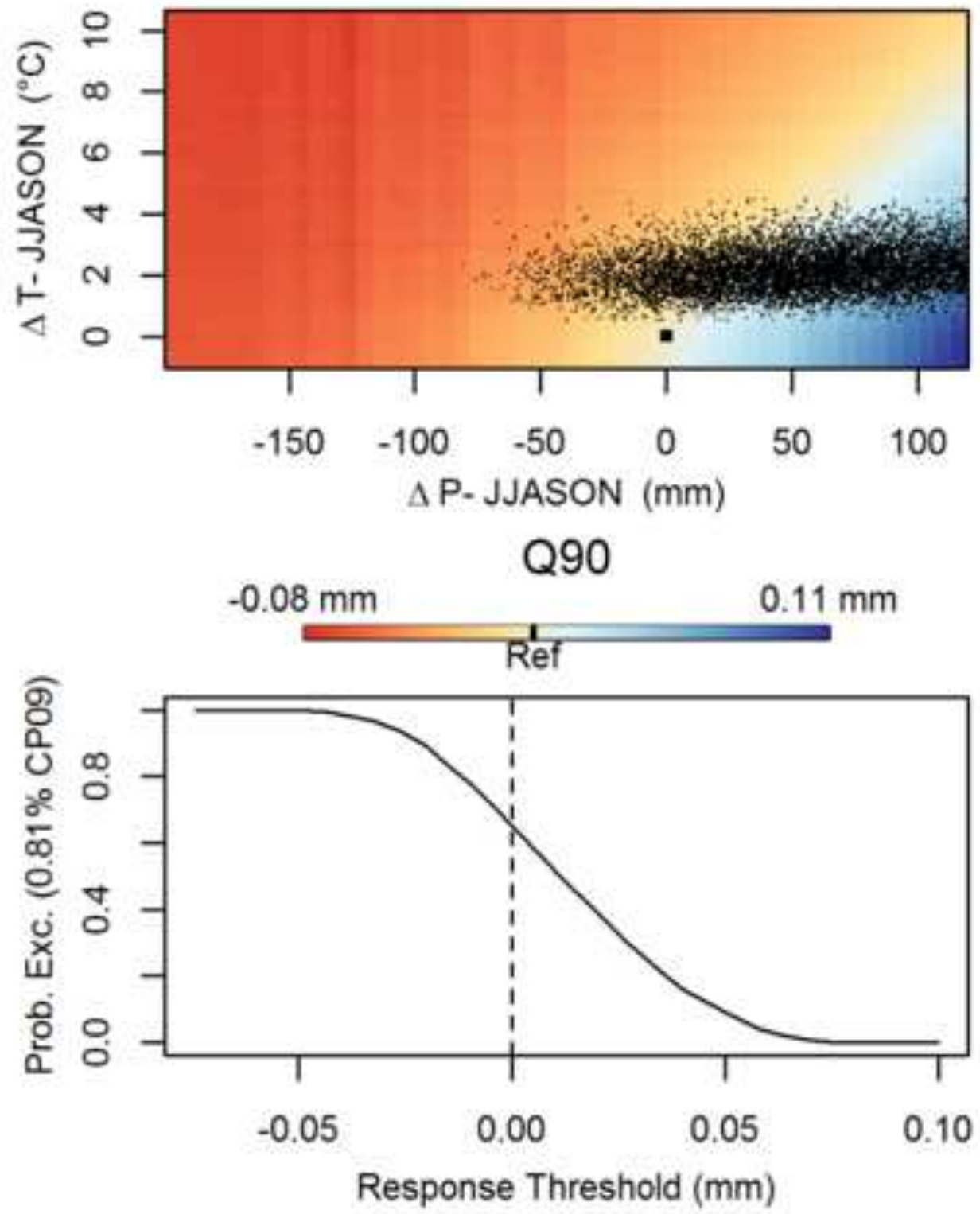